\title{
Proceedings of the British Thoracic Society
}

\author{
The 1983 Summer Meeting of the British Thoracic Society was held on 27-29 June in the University of \\ Cambridge
}

\section{BTS smoking withdrawal study: factors associated with giving up smoking}

IA CAMPBELL for BTS Research Committee In the British Thoracic Society's smoking withdrawal study $9.7 \%$ of 1550 patients successfully gave up smoking. Reasons for wanting to stop smoking, apart from improvement in health, were expense $(30 \%)$, dislike of addiction $(20 \%)$ and "dirty habit" (18\%). Concern about weight gain was expressed by $41 \%$ of men and $59 \%$ of women. Men were more successful than women and success in both sexes increased with age. Men with ischaemic heart disease did best ( $21 \%$ success). Married or single men were more likely to give up smoking than divorced or separated men. Patients whose "most important other person" was a nonsmoker did better than if such a person smoked. Women who thought they were addicted were less likely to succeed. Confidence in ability to stop smoking for a year was related to successful outcome in men. Mean weight gain in those who were successful was $5.9 \mathrm{~kg}$. Socióeconomic group, cigarette consumption, concern about weight gain and health concern were not related to outcome. Of the successes, $50 \%$ rated will power as important, and $15 \%$ mentioned illness, $13 \%$ their families and $7 \%$ their doctor. Only $1 \%$ mentioned expense. Failure was most commonly attributed to lack of will power $(28 \%)$, relief of tension by cigarettes $(24 \%)$, and addiction $(16 \%)$. Other smokers in the family and pressure at home were more important in women than men.

\section{Pulmonary sarcoidosis: a personal survey over 20 years}

RN JOHNSTON Three hundred and thirty-eight patients with pulmonary sarcoidosis under the care of one physician have been reviewed. Seventy-six were diagnosed between 1956 and 1963 or earlier and a minimum follow-up of 20 years is reported (average 22.5 years). All except six $(8 \%)$ have been traced ( $92 \%$ follow-up). Fifty-five patients have no respiratory disability after at least 20 years but 10 have $x$-ray evidence of minimal pulmonary fibrosis and three of more extensive fibrosis. Respiratory function tests at the end of the survey in 42 patients show that only $12(29 \%)$ had a transfer factor less than $80 \%$ of predicted. Fourteen patients received prednisolone for progressive or relapsing disease. None of these patients died from sarcoidosis but 16 died from other causes and eight $(10 \%)$ developed various forms of malignant disease. Among 263 patients seen subsequent to 1963 this good prognosis continues, with pulmonary fibrosis in a further four patients. Two patients have died from progressive sarcoidosis and postmortem findings are available in a further two patients, and in these four there was continuing "active" disease at the time of death. The average follow-up in this supplementary series is six years and to date there has been only one simple tumour (neurilemmoma).

\section{Treatment of pneumothorax by simple aspiration}

AAD HAMILTON, GJ ARCHER All the patients admitted to Stepping Hill Hospital with an uncomplicated pneumothorax requiring treatment during the 12 months up to January 1983 were admitted to the study. These patients, numbering 10 , were treated by simple aspiration of air using a plastic cannula used for intravenous insertion. In seven patients the procedure was successful. Of these, there has so far been only one recurrence, in a patient who had had four previous pneumothoraces. One other elderly patient developed a small ipsilateral pleural effusion which has been assumed to be neoplastic. None of the other pneumothoraces has so far recurred. Of the patients who had unsuccessful aspiration, all had severe coexisting lung disease and only one had successful re-expansion after insertion of an intercostal tube. In this small series there were only two patients with so-called benign spontaneous pneumothorax; all the others had presumed causative factors. It is concluded that simple aspiration by means of an intravenous cannula warrants further investigation.

Tuberculous lymphadenitis: results of nine-month and eighteen-month regimens after eighteen months

CR McGAVIN for the Research Committee of the BTS This multicentre study compares nine versus 18 months' chemotherapy for lymph node tuberculosis. The drug regimens comprise rifampicin and isoniazid supplemented initially by ethambutol for eight weeks. One hundred and fifty-two patients had entered the study by June 1982 . Thirty-two were withdrawn, mostly because of drug errors and non-attendance. One hundred and twenty patients, equally divided between long-course and short-course chemotherapy, have now been observed for 18 months. Seventy-four per cent were Asian (mean age 33 years) and $22 \%$ were European (mean age 50 years). In the first nine months after the start of therapy fresh nodes appeared in $12 \%$, existing nodes enlarged in $11 \%$, and $8 \%$ required further surgical procedures. In the second nine months after the start of therapy existing nodes enlarged in $6 \%$ and fresh nodes appeared in $3 \%$ of the short-course group, but there were no such events in the long-course group. No microbiological relapse has been recorded to date, but follow-up continues. 
Controlled trial of six months' chemotherapy in pulmonary tuberculosis

JH ANGEL, AR SOMNER, KM CITRON for the BTS Research Committee Two six-month regimens of isoniazid and rifampicin, supplemented for the first two months by streptomycin and pyrazinamide (SHRZ6) or by ethambutol and pyrazinamide (EHRZ6), were compared with a ninemonth regimen of isoniazid and rifampicin, supplemented for the first two months by ethambutol (EHR9). All 444 patients who completed chemotherapy had negative sputum cultures by the end of treatment, but the rate of sputum conversion was significantly more rapid with the two pyrazinamide-containing regimens. Adverse reactions were not a serious problem. Hepatitis occurred in $4 \%$ of the patients who received pyrazinamide (SHRZ6 and EHRZ6) and in $4 \%$ of patients in the regimen without pyrazinamide (EHR9). Three hundred and seventy-six patients have been followed up for three years from the end of chemotherapy. Relapses have occurred in one of 121 SHRZ6 patients, three of 126 EHRZ6 patients, and two of 129 EHR9 patients. These observations reinforce our earlier conclusion that six months' chemotherapy with these pyrazinamide-containing regimens is as effective as the currently recommended nine months' regimen and has the advantage of being shorter and cheaper while being equally well tolerated.

Controlled trial of short-course and standard-duration chemotherapy for pulmonary tuberculosis in the Algerian Sahara: Algerian working group and Medical Research Council collaborative study

JANET J DARBYSHIRE (presenter) A six-month daily oral regimen of isoniazid and rifampicin supplemented by pyrazinamide and ethambutol for the first two months has been compared with a 12-month daily oral regimen of isoniazid and ethambutol, supplemented by streptomycin for the first month, in an area of the Algerian Sahara where a substantial proportion of the population is nomadic. The study was conducted under conditions approaching those achievable in the routine treatment services and, in particular, the nomads were allowed to continue their nomadic way of life. A total of 601 patients all with a positive sputum smear in the local laboratory were admitted to the study, $28 \%$ being nomads. Confirmation of the diagnosis by culture in the reference laboratory in Algiers was possible in $70 \%$; a further $25 \%$ had confirmation either from a positive smear in the reference laboratory or from a radiographic lesion at independent assessment. In all, 95 patients were excluded, the majority because of default. For the patients known to have fully sensitive strains before treatment the 12-month regimen had an overall failure rate of $17 \%$ in 154 patients assessed at two years, significantly higher $(p<0.001)$ than the $3 \%$ of 131 patients on the six-month regimen. If we consider all patients assessed at two years, the overall failure rates were $3 \%$ of 59 nomads and $4 \%$ of 170 settled residents on the six-month regimen, compared with $14 \%$ of 58 nomads and $17 \%$ of 173 settled residents on the 12 -month regimen.
Thus the six-month regimen was superior to the 12-month regimen and for both regimens the results were as good for nomads as for the settled residents.

\section{Antihistamines in seasonal allergic rhinitis: a double-blind} study of clemastine and ketotifen

AD BLAINEY, S OLLIER, C GOULD, R DAVIES Antihistamines are widely used in the treatment of allergic rhinitis and are considered effective. It has recently been shown that ketotifen is a powerful antihistamine (Phillips et al. Br J Clin Pharmacol 1983, in press), though it is claimed that it may also have additional "antiallergic" properties. We have conducted a double-blind placebo-controlled comparison of ketotifen with clemastine, an established antihistamine, in adults with seasonal allergic rhinitis to determine whether ketotifen provides any advantage over clemastine. Forty-eight patients with seasonal allergic rhinitis due to grass pollen entered the study; 16 received ketotifen and 16 clemastine (both at a dose of $1 \mathrm{mg}$ twice daily). Sixteen received identical placebo tablets. Symptoms of rhinorrhoea, sneezing, and nasal blockage were recorded on visual-analogue scales and diary cards at three-weekly intervals throughout the summer, and doseresponse curves for the increase in nasal resistance in response to increasing doses of histamine were produced on each occasion. Symptom scores and the nasal response to histamine initially increased in all three groups but after more than six weeks of therapy both symptoms and the nasal response to histamine were significantly reduced in the ketotifen-treated group in comparison with placebo. The clemastine-treated patients showed a significant reduction in the nasal response to histamine but no improvement in symptoms. We conclude that ketotifen is effective in the treatment of seasonal allergic rhinitis in adults. This may be the result of its potent antihistaminic activity or the drug may have additional properties.

\section{Isosorbide dinitrate and isoxsuprine in exercise-induced asthma}

WM TULLETT, KR PATEL The effects of saline, isosorbide, isoxsuprine, salbutamol, and sodium cromoglycate (SCG) were compared in seven patients with exercise-induced asthma (EIA). The protective effect of isoxsuprine and isosorbide as measured by $\mathrm{FEV}_{1}$ after eight minutes of treadmill exercise was significant, being comparable to that of SCG but not as effective as salbutamol. It appears that irrespective of the mechanism of action in EIA a smoothmuscle relaxant compound which does not act via the calcium channels can afford significant protection. The fact that there was no statistical difference between isoxsuprine, isosorbide, and SCG may lend fuel to the argument that SCG's main effect in EIA is via bronchial smooth muscle and not via mast cells. Apart from beta-blockers, it is beginning to appear that all antianginal preparations have an action in EIA and we would suggest that isosorbide dinitrate would be a safe and indeed effective preparation in patients with both chronic obstructive airways disease and ischaemic heart disease. 
Incidence of cardiac dysrhythmias in asthmatic patients taking sustained-release oral $\beta_{2}$-adrenergic agonists

AH AL-HILLAWI, R HAYWARD, N McI JOHNSON We have looked at the incidence of cardiac dysrhythmias in 16 stable asthmatics (mean age 39 years, range 19-60 years) with early morning dipping who were prescribed sustained-release $\beta_{2}$-adrenergic agonists. In a single-blind crossover study patients were randomly allocated to salbutamol spandet (8 $\mathrm{mg}$ at night) for one week or terbutaline SA tablet ( $7.5 \mathrm{mg}$ twice daily) for one week with the appropriate metered-dose inhaler. Twelve-hour ECG tapes were worn overnight on the day before the trial, at the end of the first week of medication, and at the end of the second week of medication. Although no significant change in maximum heart rate was recorded with either preparation, five patients developed arrhythmias during the study. Three patients had abnormal ECG tapes before treatment: two had atrial ectopics and subsequently developed paroxysmal atrial tachycardia during the week on salbutamol spandet; and one had single ventricular ectopics progressing to paired ectopics on terbutaline SA. Two patients with normal baseline recordings developed ventricular ectopics on both salbutamol spandet and terbutaline SA. Eleven of the trial patients also recorded their PEFR recordings before going to bed and on awakening. These patients showed no significant improvement either in actual values or in the morning dips with either preparation over baseline recordings.

\section{Sympathoadrenal responses in asthma}

PW IND, MJ BROWN, PJ BARNES The physiological importance of circulating catecholamines, in particular adrenaline, in asthma is suggested by the actions of $\beta_{2}$ adrenoceptor agonists and antagonists on airway calibre, in the absence of a functional pulmonary sympathetic nerve supply. We previously reported a surprising impairment of plasma catecholamine in asthmatics developing exercise-induced asthma (EIA) compared with controls performing matched exercise (PJ Barnes et al. Thorax $1981 ; 36: 435-40)$. We have now extended these observations. In view of conflicting reports of catecholamine response to exercise in asthmatics, we performed treadmill exercise tests $\left(6 \mathrm{~min}\right.$ at $6 \mathrm{kph}$, slope $\left.8-10^{\circ}\right)$ in five male subjects (mean age $28 \pm 2.9$ (SEM) years). Maximum fall in $\mathrm{FEV}_{1}$ was $35 \% \pm 6.6 \%$ (SEM) of baseline but plasma adrenaline was unchanged and plasma noradrenaline rose by $311 \% \pm 52 \%$ from baseline five minutes after exercise, confirming our previous finding that the sympathoadrenal response to exercise is blunted in asthmatics compared with normal subjects. The catecholamine response to hypoglycaemia was investigated in five asthmatic children with EIA and five non-asthmatic controls by a standard insulin tolerance test. There was no significant difference between the groups in plasma glucose, noradrenaline, or adrenaline before or after insulin. Plasma noradrenaline rose $140 \%$ in both groups; adrenaline rose 32 -fold in the asthmatics and 28-fold in the controls. Incremental histamine infusion was also studied as a less profound stimulus to adrenaline secretion. In six normal male sub- jects (aged $30 \pm 1 \cdot 8$ years) plasma adrenaline rose $1 \cdot 2$-fold while noradrenaline was unchanged after a 15-minute infusion of histamine at $128 \mathrm{ng} / \mathrm{kg} / \mathrm{min}$. The same infusion in five atopic asthmatics ( $24 \pm 3 \cdot 2$ years) increased plasma adrenaline $3 \cdot 1$-fold, while noradrenaline rose $1 \cdot 4$-fold and peak expiratory flow fell by $16 \% \pm 8 \cdot 2 \%$ from baseline. We conclude that the sympathoadrenal response to exercise is impaired in asthmatic subjects while the response to hypoglycaemia and histamine is normal. The mechanism for this selective defect is uncertain.

\section{Hyperreactivity of the nasal airways: fact or fiction?}

OJ CORRADO, CAL GOULD, RJ DAVIES Increased reactivity of the airways is considered by some to be a cardinal feature of asthma, although the underlying mechanisms have still to be explained. The increased responsiveness of the bronchi of asthmatics to non-specific stimuli may simply be a reflection of their decreased calibre; alternatively it may be the result of true differences in behaviour of the airway, due perhaps to alteration in the function of bronchial epithelium, nerve endings, or smooth muscle. Even though it is a readily accessible organ, there have been few studies on the response of the nasal airways to non-specific stimuli. Further, apart from the vasculature, the nose is devoid of smooth muscle. We have studied the response to histamine in 20 patients with perennial rhinitis and 16 non-rhinitic control subjects. Nasal airways resistance (NAR) was measured in both nostrils by anterior rhinomanometry and repeat measurements were made two and five minutes after $100 \mu$ l of phenol saline and increasing concentrations of histamine $(1,2.5,5,10$, and $25 \mathrm{mg} / \mathrm{ml})$ had been sprayed into the nostril with the lowest resistance. There was no significant difference in NAR before provocation testing or after application of phenol saline in the patients with rhinitis compared with controls. There was a significantly greater increase in NAR following provocation with histamine $(2.5 \mathrm{mg} / \mathrm{ml})$ in the patients with perennial rhinitis compared with non-rhinitic control subjects $(p$ $<0.05)$, suggesting that nasal reactivity does indeed occur.

\section{Bronchoalveolar lavage in asthma: the efiect of sodium cromoglycate on leucocyte counts, immunoglobulins, and complement}

PATRICIA DIAZ, FR GALLEGUILLOS, M CRISTINA GONZALEZ, AB KAY In a double-blind placebo-controlled study we measured the effect of sodium cromoglycate (DSCG) on leucocyte counts, total IgE, IgG, IgA, IgM, house-dustmite(HDM)-specific IgE, C3, and C4 in bronchoalveolar lavage (BAL) fluid and peripheral blood in 36 atopic, perennial asthmatic subjects (SCG 19; placebo 17). Differential cell counts on bronchial mucus were also performed. The percentage of eosinophils in bronchial mucus and BAL fluid were significantly decreased following SCG. There was also a significant decrease in the concentration of total IgA (expressed as an IgA:albumin ratio) in BAL fluid following 28 days treatment with SCG. When the 
SCG-treated patients were divided into responders and non-responders on the basis of average daily symptom scores, the responders had a significant decrease in bronchial mucus eosinophils, BAL eosinophils, and HDMspecific IgE (but not IgA) following SCG. No significant differences in any of the measurements were observed in the non-responders. These results suggest that the efficacy of SCG in bronchial asthma might be related to its ability to suppress the local accumulation of eosinophils and specific IgE antibodies.

\section{Immunoglobulin $\mathbf{G}_{\mathbf{2}}$ deficiency in chronic and recurrent respiratory infections}

PJ STANLEY, PJ COLE Immunoglobulin (Ig) $G$ subclasses 1-4 have different biological properties. In particular, certain antibodies are subclass specific, for example, anticarbohydrate antibodies are of $\mathrm{IgG}_{2}$ subclass (Yount et al, $J$ Exp Med 1968; 127:633). Sixty-six percent of serum IgG is $\mathrm{IgG}_{1}\left(\mathrm{IgG}_{2}-23 \%, \mathrm{IgG}_{3}-7 \%, \mathrm{IgG}_{4}-4 \%\right)$ and deficiency of a subclass can occur with normal total IgG. Oxelius (Clin Exp Immunol 1974;17:19) reported IgG $_{2}$ and $G_{4}$ deficiency in a family suffering from chronic infections, mostly due to Haemophilus infuenzae, with absence of serum antibodies to $H$ infuenzae polysaccharide. Oxelius et al (New Engl J Med 1981;304:1476) reported $\mathrm{IgG}_{\mathbf{2}}$ deficiency in seven of $\mathbf{4 8}$ patients with selective IgA deficiency. We measured serum IgA, total IgG, and $\operatorname{IgG}_{1-4}$ in 80 patients (40 with bronchiectasis, 40 with recurrent respiratory infections) using radial immunodiffusion. All patients had normal or raised total IgG but 14 had low serum IgA. Deficiency of IgG was found in seven patients (five with recurrent infection, two with bronchiectasis). Five of these seven had concomitant IgA deficiency. In view of the reported beneficial response to gammaglobulin replacement in IgG subclass deficiency, the latter may be an important condition to recognise. It will not be detected if only total IgG is estimated.

\section{Radiographic changes in psittacosis infection}

II COUTTS, $S$ MACKENZIE, RJ WHITE The incidence of psittacosis has increased in recent years. Forty-four cases, serologically confirmed by the Public Health Laboratory Service, occurred in Bristol in 1980 and 1981. Eleven were managed entirely by their general practitioners. Thirtythree attended hospital and 11 were admitted. The mean age of the patients was 41.7 years (range 8-76). The initial chest film was normal in 11 of the 33 hospital attenders, including three inpatients. The most common radiographic abnormality was patchy consolidation $(64 \%)$. This was bilateral in three cases. Eleven had purely segmental consolidation. Lobar consolidation was present in five and in a further two cases more than one lobe of the lung was affected. Pleural effusion occurred twice, one being associated with consolidation. The radiograph subsequently deteriorated in only one patient. No abnormality was observed to develop in those who presented with a normal film. The consolidation showed no predeliction for any particular lobe or segment. Twelve radiographs returned to normal after a mean of 7.25 weeks (range 3-20) and a further eight had improved at final attendance after a mean of 4.4 weeks (range 1-10). There were no radiographic features that appeared to be characteristic of psittacosis infection but segmental consolidation was the commonest abnormality seen.

\section{Branhamella lower respiratory tract infection in patients with chronic lung disease}

J POWER, DF AHMAD, DT McLEOD, MA CALDER Branhamella catarrhalis is widely regarded as a commensal of the oropharynx and is therefore not commonly reported when seen on sputum examination. A few cases of $B$ catarrhalis as a pulmonary pathogen capable of producing $\boldsymbol{\beta}$-lactamase in a minority of isolates have, however, been reported (Ninane et al. Br Med J 1978;i:276-8). We report a striking increase in the incidence of $B$ catarrhalis in the sputum of patients with longstanding pulmonary disease who presented with symptoms of an infective exacerbation in November and December 1982 and January 1983. In our laboratory $B$ catarrhalis is routinely reported, the criteria for pathogenicity being: numerous pus cells in the Gram stain with intracellular and extracellular Gramnegative diplococci, a moderate-to-profuse growth of $B$ catarrhalis, and absence of any other known respiratory pathogens. Such isolates are normally very few. Transtracheal aspiration of sputum is unnecessary (Thornley $e t$ al. Br Med J 1982;285:1537-8). Of 48 cases documented, eight were in outpatients. Although one-quarter of the cases were admitted with $B$ catarrhalis, three-quarters acquired their infection in hospital. One such patient required assisted ventilation. Over $60 \%$ were $\beta$-lactamase-producing strains. We conclude that $B$ catarrhalis is a pathogen which should be looked for and reported in exacerbations of chronic chest disease as infection with a $\beta$-lactamase-producing strain may be treated with an inappropriate antibiotic.

\section{Abnormalities of the lungs and thoracic cage in the Ehlers-Danlos syndrome}

JG AYRES, FM POPE, JF REIDY, TJH CLARK Case reports of bullae, pneumothorax, and haemoptysis have all been reported in the Ehlers-Danlos syndrome (EDS) but the incidence of these complications in EDS is unknown. We studied 20 patients with fully documented EDS (10 type I, 6 type II, and 4 type IV) by measuring lung volumes, flow-volume curves, and gas transfer and by using a questionnaire. A chest radiograph was also obtained. Two patients had bullous lung disease, one having had three pneumothoraces followed by a pleurodesis. Five patients had had at least one minor haemoptysis and in two the episodes had been recurrent. One patient had tracheomegaly (the Mounier-Kahn abnormality). Gas transfer (KCO) was greater than $120 \%$ of predicted in seven patients, possibly owing to an increased intrapulmonary vascular volume. Compliance was measured in two patients; one patient showed a shift of the pressure-volume curve upwards, suggesting loss of elastic recoil, but with no clinical evidence of asthma or emphysema. The straight back 
syndrome or other thoracic skeletal abnormalities were noted in 11 patients. Type IV patients appear to be especially likely to have lung or chest wall abnormalities. In any patient with haemoptysis, bullae, or pneumothorax with no obvious cause, a diagnosis of EDS should be considered.

\section{Pulmonary embolism in children}

DJ MATTHEW, M LeVine Pulmonary embolism in childhooc is a rare but underdiagnosed condition. A recent revieu (JR Buck, RH Connors, WW Coon, et al. J Pediat Surg $1981 ; 16: 385)$ of 25 years of paediatric necropsy experience in Michigan reported an incidence of 3-7\%, of whict less than $10 \%$ had been suspected in life. While the vas majority of pulmonary emboli in adults originate in the deep veins of the pelvis and legs, these are reported to be rare sites of origin in children, the heart and vena cavac being the most common. We report the four children agec 5-13 recognised to have pulmonary emboli in our unit ove1 the last two years. Their primary diagnoses were: craniopharyngioma, asthma, chronic subacute jejunal obstruction, and Reye's Syndrome. In three the diagnoses were supported by multiple or massive perfusion defects on technetium microaggregate lung perfusion scans. The fourth and only child to die was diagnosed at necropsy. Three of the children had markedly elevated plasma osmolality, one as a consequence of his diabetes insipidus and two as a result of hyperosmolar therapy for cerebral oedema. All were treated with heparin. The child who died was found to have a femoral vein thrombosis but the sites of origin of emboli in the other children were not defined.

\section{Prediction of loading and maintenance doses of warfarin in patients with thromboembolic disease}

A FENNERTY, J DOLBEN, P THOMAS, P BENTLEY, IA CAMPBELL, PA ROUTLEDGE The chest physician has to deal frequently with thromboembolic disease and its treatment with anticoagulants. With the recommended loading dose of warfarin $(10 \mathrm{mg}$ on three consecutive days) up to one-third of patients will be above the therapeutic blood concentration range (BCR) by day 4. (PA Routledge et al. Predicting patients' warfarin requirement. Lancet 1977; i 854-5). From previous work, nomograms were constructed based on BCRs measured while the patients were on a heparin infusion. On the basis of these nomograms a flexible loading dose regimen was used, following a single $10 \mathrm{mg}$ loading dose of warfarin, and a prediction of the maintenance warfarin dose was made. In 33 consecutive patients only $6 \%$ were over-anticoagulated by day $4(70 \%$ were within the therapeutic BCR 2-4). These two patients were identified after the second loading dose, which enabled us to prevent the steeper rise in BCR that would have occurred after a conventional loading scheme. The actual maintenance dose, defined as that giving therapeutic BCRs on three consecutive occasions, each separated by at least 24 hours, correlated well with the predicted dose ( $r=$ $0.898, \mathrm{n}=33, \mathrm{p}<0.001$ ), the mean BCR being $2.45 \pm$ $0 \cdot 27$. In 31 of the subjects the actual maintenance dose was within $1 \mathrm{mg}$ of the predicted value. We believe that the use of these nomograms will improve the management of patients being anticoagulated for thromboembolic disease.

\section{Total and free plasma theophylline concentrations in obstructive airways disease}

P EBDEN, D LEOPOLD, D BUSS, AP SMITH, PA ROUTLEDGE There is marked variability in clinical response between individuals at any given total plasma theophylline concentration. A recent study showed that the fraction of theophylline free in plasma could vary more than four-fold in obstructive airways disease, which might be responsible for much of the variability in response (Lesko et al. Clin Pharmacol Ther 1981;29:776-81). We therefore measured the plasma protein binding of theophylline in plasma from 39 outpatients with obstructive airways disease receiving chronic oral theophylline therapy. The protein binding was measured at $37^{\circ} \mathrm{C}$ and $\mathrm{pH} 7.4$ by equilibrium dialysis. Total plasma theophylline concentration was measured by high-performance liquid chromatography and the free concentration calculated by multiplying total concentration by the free (unbound) fraction.

The total plasma theophylline concentration varied from 0.7 to $22.0 \mu \mathrm{g} / \mathrm{ml}$ (mean $10.6 \pm 5.3$ (SD) $\mu \mathrm{G} / \mathrm{ml} \mathrm{SD}$ ). The free fraction of theophylline varied only between 0.575 and 0.688 (mean $0.626 \pm 0.024 \mu \mathrm{g} / \mathrm{ml}$ ) and was not related to the total concentration $(r=-0.225 ; n=39 ; p>$ $0.05)$. There was therefore a very close relationship between free and total plasma concentrations $(r=0.996 ; n=$ $39 ; p<0.001)$. We conclude that there is little variability in plasma protein binding of theophylline in obstructive airways disease. Other factors appear to be responsible for variability in the response to a given total plasma theophylline concentration.

\section{Receptor patterns on lymphocytes and their modulation by drugs}

WR WILLIAMS, BH DAVIES The distribution of $\beta$ - and $\alpha$-receptors on peripheral blood cells has usually been investigated by isolated membrane techniques. These have considerable technical difficulties and are not physiological. A technique of whole viable lymphocyte binding to the tritiated $\alpha_{1}$ - and $\beta_{2}$-antagonists prazosin and dihydroalprenolol has been developed and the modulation of receptor binding by physiological mediators of asthmatic responses and commonly used anti-asthmatic drugs investigated. Results expressed as \% change in specific antagonist binding with each agent indicate that theophylline, sodium cromoglycate, salbutamol, and histamine (100 $\mu \mathrm{mol} / 1-10 \mathrm{nmol} / 1), \mathrm{PGF}_{2 \alpha}, \mathrm{PGE}_{2}$ and adrenalin substantially inhibit prazosin binding but had little or no consistent effect on dihydroalprenolol binding. Verapamil, clemastine, and ketotifen competed with both antagonists at higher concentrations $(1 \mu \mathrm{mol} / \mathrm{l})$ while cimetidine inhibited prazosin binding with less affinity for the $\beta$-receptor site. Prednisolone $(0 \cdot 1-1 \mu \mathrm{mol} / \mathrm{l})$ moderately inhibited prazosin binding $(37 \%) . \mathrm{PGE}_{2}$ and prednisolone both decreased agonist inhibition of prazosin binding. All agents investigated showed some binding to $\alpha$-receptors. Verapamil, 
clemastine, ketotifen, and to a lesser extent cimetidine, also bind to the $\beta$-receptor site. Studies to compare isolated peripheral lymphocytes and pulmonary wash lymphocytes are now in progress to indicate the meaning of these results.

\section{Adenosine-induced bronchoconstriction in asthma: specificity and relationship to airway reactivity}

HJ CUSHLEY, ST hOlgate Adenosine, a purine nucleoside, is released from lung tissue with antigen challenge and hypoxaemia, two conditions which occur during an asthma attack. We have previously shown that adenosine is a bronchoconstrictor in asthma (Cushley et al. Br J Clin Pharm 1983;15:161-5) whose effect may be competitively antagonised by low concentrations of theophylline. To define further the bronchoconstrictor effect of adenosine, 29 allergic asthmatic patients were challenged with increasing concentrations of nebulised adenosine and, on a separate occasion, histamine to assess airway reactivity. Airway responses were measured as specific conductance (sGaw). Both adenosine and histamine caused bronchoconstriction, concentrations producing a $40 \%$ fall in sGaw $\left(\mathrm{PC}_{40}\right)$ being $0.86 \pm 0.18$ (mean \pm 1 SEM) and $0.24 \pm 0.07 \mathrm{mg} / \mathrm{ml}$ respectively. Airway reactivity $\left(\mathrm{PC}_{40}\right)$ to adenosine correlated closely with that to histamine $(r=0.59, p<0.001)$. The specificity of adenosine's response was investigated in eight asthmatic subjects, who were challenged with increasing concentrations of adenosine, its parent nucleotide $5^{\prime}$ adenosine monophosphate (AMP), and its principle breakdown product, inosine. Adenosine and AMP caused similar bronchoconstriction $\left(\mathrm{PC}_{40}, 1.46 \pm 0.51,2.99 \pm\right.$ $1.15 \mathrm{mg} / \mathrm{ml}, \mathrm{p}>0.005)$, whereas inosine was without effect. Thus adenosine and AMP (which can be metabolised to adenosine) are potent bronchoconstrictors whose effects are mediated by factors related to airway reactivity.

\section{Influence of airway reactivity on circulating histamine and neutrophil chemotactic activity}

PH HOWARTH, GJ-K PAO, SR DURHAM, TH LEE, AB KAY, HOLGATE ST Controversy exists over the detection of plasma histamine change following allergen-induced bronchoconstriction in asthma. To investigate this histamine and neutrophil chemotatic activity (NCA) were measured in peripheral blood following antigen challenge in two groups of six asthmatics, one with hyperreactive airways and one with less reactive airways. Following challenge a $38.5 \pm$ $5.3 \%$ fall in $\mathrm{FEV}_{1}$ in the group with hyperreactive airways was accompanied over the same time course by a $78.8 \pm$

Severity of asthma, airways reactivity, and sensitivity to antigen (mean values $\pm S E M$ ) in asthmatics with hyperreactive $(H A)$ and less reactive airways

\begin{tabular}{lrlll}
\hline Subjects & $\begin{array}{l}\text { FEV } \\
\text { predicted })\end{array}$ & $\begin{array}{l}\text { Methacholine } \\
P C_{20}(m g / m l)\end{array}$ & $\begin{array}{l}\text { Antigen } \\
\text { skin weal } \\
(\text { mm })\end{array}$ & $\begin{array}{l}\text { Antigen } \\
\text { dilution } \\
\text { inhaled }\end{array}$ \\
\hline HA & $\begin{array}{r}97.3 \pm 5.1 \\
\text { LRA }\end{array}$ & $\begin{array}{l}0.09(3.2 \pm 3.7 \\
11.89(1.023-0.25)\end{array}$ & $\begin{array}{l}12.6 \pm 1.54 \\
17.8 \pm 3.15\end{array}$ & $\begin{array}{l}1.92 \times 10^{-2} \\
2.92 \times 10^{-3}\end{array}$ \\
\hline
\end{tabular}

$15.4 \%$ increase in NCA, but no significant change in plasma histamine from a mean baseline of $3.75 \pm 0.59$ nmol/l. In contrast, a $29.4 \pm 4.3 \%$ fall in $\mathrm{FEV}_{1}$ in the group with less reactive airways was associated with no significant change in NCA despite an increase in plasma histamine from a mean baseline of $1.66 \pm 0.36 \mathrm{nmol} / \mathrm{l}$ to $4.44 \pm 0.09 \mathrm{nmol} / \mathrm{l}$ five minutes after challenge. These findings support the idea that with antigen challengè less intrapulmonary mediator release is required to produce equivalent bronchoconstriction in patients with hyperreactive airways than in those with less reactive airways. The absence of NCA change in those with less reactive airways, in contrast with those with hyperreactive airways implies a separate source of NCA from histamine. This study emphasises the importance of subjects' antigen sensitivity and airway reactivity as separate factors influencing the peripheral detection of mediators following antigen challenge.

\section{Effect of corticosteroids on lung $\beta$-adrenergic receptor site} concentration and afínity

PDJ HANDSLIP, JPT WARD, IR CAMERON Corticosteroids have been shown to potentiate the bronchodilator response and to restore $\beta$-agonist sensitivity in asthmatics. We have investigated the effect of hydrocortisone on the density and affinity of $\boldsymbol{\beta}$-adrenergic receptors in a rat lung membrane preparation. Male CSE rats (200-270 g) received intraperitoneal injections of hydrocortisone. Group 1 received $50 \mathrm{mg} / \mathrm{kg} /$ day and group $24 \mathrm{mg} / \mathrm{kg} /$ day for 14 days, and group 3 received $10 \mathrm{mg} / \mathrm{kg} /$ day for seven days. The respective control groups received $0.2 \mathrm{ml}$ sterile water daily. A lung membrane suspension was prepared and $\beta$-adrenergic receptor site concentration (Bmax) and affinity $\left(K_{D}\right)$ was determined with specific ${ }^{3} \mathrm{H}$ dihydroalprenolol binding and liquid scintillation counting. Results were calculated with a weighted least-squares curve-fitting algorithm ("Ligand," a modified form of Scatchard plot). In group $1 \mathrm{Bmax}$ increased from $391 \pm 22$ (SEM) $\mathrm{fmol} / \mathrm{mg}$ in the controls to $492 \pm 22 \mathrm{fmol} / \mathrm{mg}$ in the treated group $(\mathrm{p}<0.005 ; \mathrm{n}=20)$. In group $2 \mathrm{Bmax}$ increased from $325 \pm 22 \mathrm{fmol} / \mathrm{mg}$ to $620 \pm 69 \mathrm{fmol} / \mathrm{mg}$ (p $<0.001 ; n=20)$. In group $3 \mathrm{Bmax}$ increased from $592 \pm$ $36 \mathrm{fmol} / \mathrm{mg}$ to $789 \pm 70 \mathrm{fmol} / \mathrm{mg}(\mathrm{p}<0.005 ; \mathrm{n}=17)$. Affinity $\left(K_{D}\right)$ was not significantly different between controls and treated in any group. We have clearly shown an increase in lung $\beta$-adrenergic receptor site concentration with hydrocortisone treatment at three different dose levels and after one and two weeks duration of treatment. We suggest that this is a possible mechanism of action of corticosteroids in asthma.

\section{Relationship between in vivo airway responsiveness and in} vitro smooth muscle sensitivity to methacholine in man

JA ROBERTS, D RAEBURN, IW RODGER, NC THOMSON Airway responsiveness to methacholine varies between normal subjects and is increased in certain respiratory disorders. The importance of airway smooth muscle sensitivity in determining in vivo responsiveness is unknown. We have 
examined this by comparing in vivo airway responsiveness with in vitro airway smooth muscle sensitivity to methacholine in 10 patients (age range 43-69 years) undergoing thoracic surgery. In vivo responsiveness was determined by administration of inhalations of doubling concentrations of methacholine with a modification of the method of Cockcroft et al (Clin Allergy 1977;7:235-43). Results were expressed as the provocation concentration causing a decrease in forced expiratory volume in one sec of $20 \%\left(\mathrm{PC}_{20}-\mathrm{FEV}_{1}\right)$ and in specific conductance of $35 \%$ $\left(\mathrm{PC}_{35-s G a w}\right)$. In vitro airway smooth muscle sensitivity was determined on specimens obtained at thoracotomy. Log dose-response curves for methacholine were constructed and the concentration causing a $50 \%$ maximum contraction $\left(\mathrm{ED}_{50}\right)$ was derived. $\mathrm{PC}_{20}-\mathrm{FEV}_{1}$ ranged from 0.9 to $61.3 \mathrm{mg} / \mathrm{ml}$ and $\mathrm{PC}_{35-\mathrm{sGaw}}$ from 0.9 to $16.5 \mathrm{mg} / \mathrm{ml}$. There was no significant correlation between $\mathrm{PC}_{20}-\mathrm{FEV}_{1}$ and $\mathrm{ED}_{50}$ $(\mathrm{r}=-0.35)$ or between $\mathrm{PC}_{35-\mathrm{sGaw}}$ and $\mathrm{ED}_{50}(\mathrm{r}=-0.03)$. These results suggest that other factors, rather than smooth muscle sensitivity alone, must influence in vivo airway responsiveness to methacholine.

\section{Pulmonary platelet accumulation in antigen-induced bronchoconstriction}

PJ THOMPSON, CP PAGE, W PAUL, J MORLEY IgE-mediated activation of basophils or alveolar macrophages from experimental animals or man causes release of the phospholipid PAF-acether. Both PAF-acether and platelets appear to play a part in antigen-induced anaphylaxis in rabbits and intravenous PAF-acether produces plateletdependent bronchoconstriction in the guinea pig. Continuous monitoring techniques have been used to measure simultaneously bronchoconstriction and platelet accumulation in the lungs of sensitised guinea pigs challenged with antigen. Platelet accumulation in the lungs was detected using "1'In-labelled platelets as described elsewhere (Page et al. Thromb Haemostas 1982;47:210) and bronchoconstriction was measured as resistance to lung inflation in anaesthetised, artificially ventilated animals. The guinea pigs were immunised with albumin in Freund's complete adjuvant four to five weeks before the experiments. In the sensitised animals intravenous challenge with ovalbumin 1 $\mathrm{mg} / \mathrm{kg}$ consistently produced both bronchoconstriction and platelet accumulation in the lungs. Lower doses of antigen $(10-100 \mu \mathrm{g} / \mathrm{kg})$, however, frequently induced platelet accumulation in the absence of significant bronchospasm. Thus antigen-induced bronchoconstriction in sensitised guinea pigs appears not to be triggered by platelet accumulation per se and may, like PAF-acether induced bronchospasm, be dependent on a platelet release reaction.

\section{Inhibition of bronchoconstriction stimulated by respiratory heat loss: comparison of cromoglycate powder and pressurized aerosol}

KM LATIMER, RS ROBERTS, MM MORRIS, FE HARGREAVE The magnitude of protective effect of sodium cromoglycate (SCG) delivered as a pressurised aerosol against bron- choconstriction stimulated by respiratory heat loss (RHL) has not been examined. We compared the effect of three doses of SCG given as pressurised aerosol $(2,10,20 \mathrm{mg})$ with SCG powder $(20 \mathrm{mg})$ and placebo (two tests) in 10 adult asthmatics. The test medications were inhaled in random order, double blind, 20 minutes before eucapnic hyperventilation of subfreezing dry air $\left(-15^{\circ} \mathrm{C}, 0 \%\right.$ humidity) in two-fold doubling volumes as described by O'Byrne et al (Am Rev Respir Dis 1982;125:281-5). Results were expressed as the provocative dose of respiratory heat loss to cause a decrease in $\mathrm{FEV}_{1}$ of $15 \%\left(\mathrm{PD}_{15}\right)$. Two way analysis of variance was applied to the group mean values. Baseline FEV, exceeded $85 \%$ predicted normal and did not differ between tests $(p>0.05)$. Premedication caused a small decrease in $\mathrm{FEV}_{1}$, which was greater after placebo than SCG $(p<0.001)$ but was not different after any dose of SCG. After placebo the intraclass correlation for $\mathrm{PD}_{15}$ was $94 \%$. All doses of SCG shifted the respiratory heat loss dose-response curve to the right. The mean \pm SD of $\mathrm{PD}_{1 \mathrm{~s}}(\mathrm{kcal} / \mathrm{min})$ were $1.64 \pm 0.37$, and $1.59 \pm 0.42$ after placebo; $2.00 \pm 0.62,1.99 \pm 0.52$, and $2.01 \pm 0.58$ after 2,10 , and $20 \mathrm{mg}$ of SCG aerosol; and $1.94 \pm 0.47$ after SCG powder. The effect of each dose of SCG was greater than placebo $(p<0.0001)$ but was not different between any dose of SCG. We conclude that the magnitude of effect of $2 \mathrm{mg} \mathrm{SCG}$ aerosol is as great as that of $20 \mathrm{mg}$ aerosol or powder.

\section{Effect of route of administration on the guinea pig pulmonary mechanical responses to $\mathrm{LTC}_{4}$ and the modification of these responses by indomethacin}

AG LEITCH, EJ COREY, KF AUSTEN JM DRAZEN Leukotriene (LT) $\mathrm{C}_{4}$ is one of the components of slow-reacting substance of anaphylaxis, which may be implicated in asthma. Intravenous administration of $\mathrm{LTC}_{4}(1 \mu \mathrm{g} / \mathrm{kg})$ to four anaesthetised, mechanically ventilated guinea pigs caused decrements in lung dynamic compliance (Cdyn) and conductance $(\mathrm{GL})$, which were maximal 30 seconds after injection and persisted for 20-30 minutes. In another four animals pretreatment with indomethacin $(30 \mathrm{mg} / \mathrm{kg}$ intraperitoneally) abolished the early ( $<1$ minute) fall in Cdyn and GL, maximal decrements now occurring at five minutes; significantly attenuated the fall in Cdyn at all time points; and significantly potentiated the fall in $\mathrm{GL}$ from three to five minutes after the infusion. Administration of 30 tidal volumes of aerosolised $\mathrm{LTC}_{4}$ (nebuliser concentration $1 \mu \mathrm{g} / \mathrm{ml}$ ) to four guinea pigs caused decrements in Cdyn and GL that were maximal five minutes after administration, persisted for 20-30 minutes, and were significantly potentiated by indomethacin pretreatment. These findings suggest that $\mathrm{LTC}_{4}$ has a primary bronchoconstrictor action on the guinea pig lung, which is modulated by the generation and release of cyclo-oxygenase products that cause an early ( $<1$ minute) and short-lived bronchoconstriction and a later (3-5 minutes) bronchodilatation when $\mathrm{LTC}_{4}$ is given intravenously. With local administration by aerosol only the bronchodilator cyclooxygenase component is found, an observation which may have importance for the phenomenon of analgesic-induced asthma. 
Use of prophylactic drugs for wheeze in general practice

AG WARDMAN, NJ COOKE Good control of asthma often depends on appropriate prophylaxis, but there are few community-based data concerning its use. From 1982 to 1983 we interviewed 312 patients (aged 16-80) from five group practices in three cities, all on regular treatment for wheeze to assess prophylactic drug use. One hundred and fifty-seven $(50 \%)$ patients used prophylaxis. Ninety-eight of the $157(62 \%)$ used inhaled corticosteroids (aerosol 86, dry powder 12), 54 (34\%) sodium cromoglycate (compound 30 , plain 20 , aerosol four), $33(21 \%)$ systemic corticosteroids, and three (2\%) ketotifen. Fifty-six (39\% of prophylactic inhaler users) missed one or more treatments per day, usually the lunch-time dose of a fourtimes-daily regimen. Fifteen $(11 \%)$ used their inhalers entirely on demand, and 19 (21\% using aerosol prophylaxis) had an inefficient inhaler technique. Seventeen compliant patients ( $12 \%$ of inhaler users) were prescribed below-standard doses ( $<400 \mu \mathrm{g}$ inhaled corticosteroid or $<4$ caps sodium cromoglycate per day) and 28 (20\%) standard doses even though both groups had symptom scores suggesting that higher doses or additional therapy may have been beneficial. Fourteen of $33(42 \%)$ patients on systemic corticosteroids were receiving no inhaled corticosteroids. Prophylactic drugs are prescribed commonly in general practice. This study shows that the main problems in their use are poor compliance and inhaler technique, the use of prophylactic drugs on demand, and under-prescription by the doctor.

\section{Effect of oral aminophylline on asthmatics maximally} bronchodilated with nebulised salbutamol

NC BARNES, JR WEBB The increase in bronchodilatation achieved by oral theophylline over maximal bronchodilatation achieved with nebulised salbutamol was studied in nine patients with stable asthma (seven men, two women), average age 54 years (range $36-66$ years), in a doubleblind, placebo-controlled, randomised, crossover trial. None of the patients was taking theophyllines and all refrained from taking $\beta_{2}$-agonists for 12 hours before the study. Two sets of baseline measurements of FEV, $\mathrm{VC}$, and SGAW were made half an hour apart. The patients were then given enough slow-release aminophylline tablets to give a therapeutic level of theophylline or matched placebo tablets. After one and a half hours FEV, VC, and sGaw were measured. The patients were given salbutamol $2 \mathrm{mg}$ via a nebuliser four times in the next two and a half hours in an attempt to achieve maximal bronchodilatation. After the last dose of salbutamol FEV, VC, and sGaw were measured and blood was taken for measurement of theophylline level. The mean theophylline level was 11.5 (range 8.5-15.1) $\mathrm{mg} / \mathrm{l}$. The increase in FEV, $\mathrm{VC}$, and sGaw was higher after aminophylline and salbutamol than it was after salbutamol alone. The mean increases for salbutamol alone were: $\mathrm{FEV}_{1} 0.75 \pm 0.31$ l; VC $0.85 \pm 0.43$ l; and sGaw $0.50 \pm 0.39 \mathrm{~s}^{-1} \mathrm{kPa}^{-1}$. The mean increases for salbutamol and aminophylline were: $\mathrm{FEV}_{1} \mathbf{0 . 8 3} \pm \mathbf{0 . 3 7} \mathrm{l}$; VC $1.00 \pm 0.571$; and sGaw $1.23 \pm 1.3 \mathrm{~s}^{-1}$. These differ- ences were not statistically significant. We conclude that the additional therapeutic action of oral theophylline over maximal bronchodilatation with nebulised salbutamol in patients with chronic stable asthma is small.

\section{Acute and domiciliary study of terbutaline inhalation via a} conical spacer in severe and chronic asthma

JOHN F O'REILLY, GRAHAM GOULD, G LASZLO We have compared the bronchodilator response to terbutaline inhalation given by pressurised aerosol (PA), pressurised aerosol fitted with a conical spacer (CS), and Acorn nebulizer (AN) in 10 patients with severe chronic asthma (mean age 52 years; range $24-72$ years. Mean $F_{1} V_{1} 1 \cdot 26$; range 0.7-2.2 litres. Mean FVC 2.6 litres; range 1.9-3.7 litres). Patients were given cumulative doubling doses of terbutaline $(0.5+1.0+4.0 \mathrm{mgs})$ in random order, using each technique, on three days within one week. FEV, and FVC were measured before terbutaline administration and 20 minutes after each dose. Nine patients completed a domiciliary trial of terbutaline $1.0 \mathrm{mg}$ thrice daily, administered by PA and CS in random order, each for two weeks, They made thrice daily assessments of PEFR and severity of symptoms. In the acute dose response study there was a significantly greater mean percentage rise in $\mathrm{FEV}_{1}$ at a dose of $0.5 \mathrm{mg}$ for both $\mathrm{CS}(21.2 \%)$ and AN (18.2\%) compared with PA $(5.6 \%)(p<0.05)$. There was a significantly greater rise in FVC at a dosage of $0.5 \mathrm{mg}$ after AN $(14.6 \%)$ compared with PA $(3.7 \%),(p<0.01)$. There were no significant differences between the responses of FVC to CS (9.7\%), PA, and AN. The domiciliary study showed significant differences in mean daily PEFR between PA (325 litres/min) and CS (275 litres/min) and in symptoms of asthma.

\section{Effect of salbutamol delivered by metered-dose inhaler} and jet and ultrasonic nebuliser on FEV and heart rate in patients with chronic asthma

JN STAINFORTH, PJ STURGISS, AE TATTERSFIELD Inhalation of $\beta_{1}$ agonists can be achieved by metered-dose inhaler (MDI) or nebuliser, the nebulised droplets being generated by air jet or ultrasonic disruption. We compared the bronchodilatation and change in heart rate after inhaled salbutamol delivered by jet nebuliser (Inspiron Mini-Neb), ultrasonic nebuliser (Pulmasonic), and MDI in patients with chronic asthma. Seven patients (two men, five women) with chronic, stable asthma were studied on three separate occasions. The mean age was 62 years (52-72) and mean FEV, 1.25 1. After baseline measurements, salbutamol was inhaled from an MDI or jet or ultrasonic nebuliser at $\mathbf{1 0}$ minute intervals to provide a cumulative dose of 5,000 $\mu \mathrm{g}$. FEV , FVC, and heart rate were measured 10 minutes after each dose. Mean baseline values of FEV, FVC, and heart rate were similar on each study day. The mean maximum increase in FEV, and FVC from baseline was 0.71 and 0.911 for the jet nebuliser, 0.74 and 0.981 for the ultrasonic nebuliser, and 0.80 and 0.941 for the MDI. There were no significant differences in $\triangle F E V_{1}$ 
or $\triangle F V C$ at any dose. After $5000 \mu \mathrm{g}$ of salbutamol, heart rate was unchanged with the jet nebuliser $(-1$ beats $/ \mathrm{min})$ and the ultrasonic nebuliser $(+3$ beats $/ \mathrm{min})$, but had increased by 19 beats $/ \mathrm{min}$ with the MDI $(p<0.025)$. The greater increase in heart rate with the MDI is likely to be due to greater absorption from the lung with this method of inhalation. For this reason the MDI is unsatisfactory for administering high doses of $\beta$-agonists.

\section{Progressive exercise training: subjective and objective changes}

HA BOOKER, DJ HARRIES, MA REHAHN, DV GASKELL, BA WEBBER, AJ DAVIS, JV COLLINS Improvement in exercise tolerance following periods of progressive exercise training for patients with chronic airways obstruction has led to this being a generally accepted form of treatment. One hundred and twenty-eight patients with severe irreversible airways obstruction and exercise tolerance limited by breathlessness took part in a double blind, controlled trial. Objective assessments of lung function and six-minute walking distance and subjective assessment from a questionnaire were carried out before a nine-week course of one of three regimens: (1) control (C); (2) exercise training (E); (3) exercise with breathing control (P). Reassessments were carried out at three, six, and 12 months following the initial assessment. While there were several significant changes in lung function within the groups, particularly the $\mathbf{P}$ group, the actual changes were clinically unimportant. Subjective improvement of both the $P$ and the $E$ groups was significantly greater than that of the $C$ group $(p<0.001)$ at three months. This difference and the improvement were maintained at 12 months, and the improvement in the $\mathbf{P}$ group was significantly greater than that of the $E$ group at $6(p<0.01)$ and 12 months $(p<0.05)$. In the absence of objective improvement, considerable subjective benefit obtained with exercise training may be enhanced by teaching breathing control. These subjective changes were maintained without constant clinic visits for reinforcement.

Response of the pulmonary circulation to oral pirbuterol in patients with chronic airflow obstruction

AJ PEACOCK, C BUSST, DM DENISON In 1981 the MRC working party reported that domiciliary oxygen therapy reduced mortality from chronic hypoxic bronchitis and emphysema. It is likely that this effect was due in part to a fall in pulmonary vascular resistance (PVR). Oxygen therapy is expensive and difficult to administer and it would be an advantage if oral therapy had a similar beneficial effect. Pirbuterol, a $\boldsymbol{\beta}_{2}$-agonist, has been reported to reduce PVR in such patients so we studied nine people with chronic airflow obstruction $(F E V, 757 \pm$ SEM $94 \mathrm{ml})$ and arterial hypoxaemia $\left(\mathrm{PaO}_{2} 8.43 \pm 0.51 \mathrm{kPa}\right)$ before and after 15 $\mathrm{mg}$ oral pirbuterol. Maximum haemodynamic effects occurred 30 minutes after the administration of the drug. Mean pulmonary artery pressure was not changed significantly but PVR fell by $19 \% \pm 6 \%$ and cardiac output rose by $24 \% \pm 8 \%$. However, these changes were accompanied by a fall in $\mathrm{PaO}_{2}$ of $7 \cdot 4 \% \pm 2 \cdot 4 \%$. We conclude that while pirbuterol causes a significant fall in PVR $(p<0.02)$, this occurs at the cost of a significant fall in $\mathrm{PaO}_{2}$ $(p<0.02)$. One explanation for this finding is that pirbuterol reverses a functionally necessary vasoconstriction whereas oxygen reverses the need for one.

Correlation between a respiratory questionnaire and peak flow measurements in printing workers exposed to a contaminated humidifier

P SHER WOOD BURGE, CAC PICKERING, NIGEL HORSEFIELD A survey of a printing works identified 37 workers with humidifier fever or respiratory symptoms, or both, who improve away from work by self-administered respiratory questionnaire. An attempt was made to validate the questionnaires by issuing each worker with a peak flow meter with written instructions to record peak flow every two hours from waking to sleeping for 14 days. Five workers returned incomplete records, leaving 32 workers with completed questionnaires and peak flow records, which were assessed blindly by defined criteria. Sixteen workers had records indicating asthma (diurnal variation in peak flow exceeding $20 \%$ after the first two days). Of these, only nine had attacks of wheezing or whistling in the chest with breathlessness, although all responded to the less specific question "Does your chest ever feel tight or your breathing become difficult?" Wheezing or whistling in the chest with rest day improvement occurred in 15 workers: consistent deterioration in peak flow at work was seen in eight of these and a further three had a history of humidifier fever. Breathlessness with rest day improvement was present in 18 workers: consistent deterioration at work was seen in 11 , and a further four had symptoms of humidifier fever. Excluding the workers with humidifier fever alone it was possible to validate the questionnaire with peak flow readings in at least $75 \%$ of workers.

\section{Effects of exercise on the regional deposition of an inhaled aerosol}

HW CLAGUE, D AHMAD, MJ CHAMBERLAIN, WKC MORGAN, S VINITSKI We have investigated the deposition of an inhaled radioaerosol at rest and during moderate exercise in eight normal subjects and five control smokers to determine whether the increased ventilation of exercise has an important influence on the regional deposition of inhaled particles. Exercise produced an increase in the total amount of aerosol deposited with proportionately greater tracheobronchial deposition, especially in smokers. In consequence, the central-to-peripheral gradient for aerosol deposition, which was significant only in smokers at rest $(p<0.05)$, became significant in both groups on exercise $(\mathrm{p}<0.001)$. The distribution pattern for zonal tracheobronchial deposition on exercise was the same in both groups, with greatest tracheobronchial deposition in the upper zone, less in the lower zone, and least in the middle zone. In addition, in the upright position at rest there was a marked gradient for alveolar deposition increasing from 
apex to base, which corresponded to the gradient for regional ventilation. On exercise aerosol deposition was more uniform and the previous interzonal differences disappeared except in smokers, whose alveolar deposition in the upper zone remained significantly less $(p<0.01)$ than that in the lower zone. The relative increase in particle deposition which occurs in the upper zones on exercise and the difference between smokers and non-smokers may be important in the pathogenesis of occupationally related dust-induced lung disease.

\section{Pulmonary efifects of experimental exposure of normal subjects to dust from dew-retted flax and from dew-retted steamed flax}

JP JAMISON, JHM LANGLANDS, RC LOWRY, CC BODEL Forced expiratory measurements were made on 12 normal subjects before and after breathing flax dust dispersed in room air at a concentration of $5 \mathrm{mg} \mathrm{m}^{3}$, with a mean particle size of $4 \mu \mathrm{m}$. The subjects were divided randomly into two groups to breathe the dust from dew-retted flax and from dew-retted steamed flax in two six-hour periods, two weeks apart, in a double-blind crossover trial. Probability levels were determined by analysis of variance. The results showed significant diminution of forced expiratory volumes and flow rate after exposure to dust $(p<0.01)$. After dust from steamed flax the diminution in pulmonary function was significantly less than after untreated flax dust $(p<0.05)$. It is suggested that steaming of flax might help to prevent byssinosis.

Means ( $\pm S E M)$ ( $l$ and $\left.l s^{-1}\right)$ of three forced expirations by 12 subjects before dust inhalation and the changes after inhalation

\begin{tabular}{|c|c|c|c|}
\hline & & Untreated & Steamed \\
\hline $\begin{array}{l}\text { Before } \\
\begin{array}{l}\text { After } 6 \mathrm{~h} \\
\text { minus before }\end{array}\end{array}$ & $\begin{array}{l}\left\{\begin{array}{l}\text { FEV } \\
\text { FVC } \\
\text { FEF } 50 \% \mathrm{~V}\end{array}\right. \\
\left\{\begin{array}{l}\Delta \mathrm{FEV} \\
\Delta \mathrm{FVC} \\
\Delta \mathrm{FEF} 50 \% \mathrm{~V}\end{array}\right.\end{array}$ & $\begin{array}{l}3.92( \pm 0.09) \\
5.34 \\
4.04 \\
-0.29 \\
-0.22 \\
V-0.57\end{array}$ & $\begin{array}{l}3.97( \pm 0.09) \\
5.40( \pm 0.11) \\
4.14( \pm 0.19) \\
-0.18 \\
-0.15 \\
-0.49\end{array}$ \\
\hline
\end{tabular}

\section{Occupational asthma in a printing factory with a contaminated humidifier}

P SHERWOOD BURGE, NIGEL HORSEFIELD, CAC PICKERING Humidifier fever is now well recognised in workplaces with contaminated humidifiers. So far there have been no reports of occupational asthma from this cause. We have investigated a printing works where occupational asthma was documented in 10 workers. A further five workers had consistent deterioration at work and improvement away from work with a diurnal variation in peak flow of less than $20 \%$. Workers with maximal reactions on the first day of work (four) were the minority. Their reactions were less consistent than those with equal deterioration each work day (three), or progressive deterioration during the working week (four). A new pattern of deterioration was seen in four workers, whose maximum deterioration was mid week with improvement at the end of the week despite con- tinued exposure. Neither immediate skinprick tests nor serum precipitins to humidifier antigens were helpful in diagnosis.

\section{Microbiological investigation of farmer's lung disease in Somerset 1963-83}

JP ANDERSON, FB GREATOREX From 1963 to 198346 patients with proved farmer's lung disease were studied. All were precipitin positive for Micropolyspora faeni and 14 also for Thermoactinomyces vulgaris. Thirty two of the patients had $M$ faeni cultured from their sputum after incubation at $55^{\circ} \mathrm{C}$ for four days; from nine of these sputa $T$ vulgaris was also grown. A 12 month survey reported from Taunton Public Health Laboratory Service Laboratory in 1976, in which 1300 consecutive non-tuberculous sputa had been cultured for thermophilic organisms, had produced 16 isolates of $M$ faeni and nine of $T$ vulgaris; 14 of the 20 patients concerned were precipitin positive, the other six were negative or untested; all were farmers. From 1975 to 1983222 sputa were selectively cultured, with thermophilic isolates from 21 patients, 14 of whom were precipitin positive. The two organisms were readily isolated from the farm environments of three patients. Fibreendoscopic bronchial aspirates were obtained from four patients with positive sputa, $M$ faeni being isolated from one specimen. No sputum surveys of the general farming population are yet available; but the apparent clinical value of thermophilic isolates has been shown. In acute farmer's lung disease there is the possibility of bronchopulmonary colonisation. Steroid treatment is of value in acute farmer's lung disease, and tetracycline has helped some patients with chronic farmer's lung disease. Airstream helmets are an efficient means of prevention.

\section{Small-cell carcinoma of the lung: survival after surgical resection}

GN MORRITT, DJL MALONEY, D LAMB, PR WALBAUM During 1968-72 854 thoracotomies for lung cancer were carried out in the department of thoracic surgery at the City Hospital in Edinburgh. The histological sections of all cases have been reviewed by DJLM and DL. One hundred and thirty-five small-cell carcinomas were identified, of which 36 were considered unresectable. Of the 99 cases of small-cell carcinoma resected, there were 40 lobectomies and 59 pneumonectomies. The overall five-year survival was $14 \%$. Of the survivors, six had had lobectomies and eight pneumonectomies. Hilar nodes were affected by tumour in five of the survivors, two of whom had had lobectomy and three pneumonectomy. The value of surgical treatment of small-cell carcinoma is not adequately reflected by the simple percentage five-year survival; it is important to relate this to the total number of small-cell carcinomas. As no absolute data are available, comparison with the numbers of patients with other cell types operated on in the same series gives some guide. Over the same five-year period 360 squamous-cell carcinomas were resected. As there are about twice as many squamous cell car- 
cinomas as small-cell carcinomas this means that small-cell carcinomas had half the resection rate of squamous carcinomas. This value of $10 \%$ for the resection rate in small-cell carcinoma, though small, is greater than current opinion would suggest.

\section{Efiect of erythrapheresis on the gas transfer for carbon monoxide and its subdivisions in polycythaemia secondary to hypoxic lung disease}

JA WEDZICHA, FE COTTER, PJW WALLIS AC NEWLAND, DW EMPEY We have used the technique of erythrapheresis, a method of isovolaemic haemodilution, in 10 patients with polycythaemia secondary to chronic obstructive bronchitis (mean $\mathrm{PaO}_{2} 6.9 \mathrm{kPa} ; \mathrm{FEV}_{1} 0.85 \mathrm{l}$ ) to investigate the effects of reduction of packed cell volume on the gas transfer for carbon monoxide and its subdivisions pulmonary capillary blood volume (Vc) and membrane diffusing capacity (DM). Erythrapheresis was performed without change in blood velume with the Haemonetics V50 blood processor. After removal of a mean red cell volume of $645 \mathrm{ml}$, the mean microhaematocrit fell from 0.58 to 0.47 , the mean blood viscosity decreasing significantly at both high and low shear rates $(p<0.01)$. After erythrapheresis there was a trend to increase in the transfer factor (TLCO) and in the transfer coefficient (KCO). The mean pulmonary capillary blood volume (VC \pm SD) was reduced before treatment at $30.2 \pm 12.2 \mathrm{ml}$ and increased significantly to $51.9 \pm 20.9$ $\mathrm{ml}$ after erythrapheresis $(\mathrm{p}<0.02)$. There was no change in membrane diffusing capacity, blood gases, or lung volumes. The mean VC remained unchanged in 10 control non-polycythaemic patients (mean $\mathrm{PaO}_{2} 7.7 \mathrm{kPa} ; \mathrm{FEV}_{1}$ 1.01) who did not have erythrapheresis and were assessed on two corresponding occasions $(65.5 \pm 22.5 \mathrm{ml} ; 64.3 \pm$ $25 \cdot 2 \mathrm{ml}$ ). Pulmonary capillary blood volume increases following erythrapheresis. This may be due to an improvement in pulmonary blood flow caused by a fall in blood viscosity and pulmonary vascular resistance, or it may be a consequence of a rise in cardiac output.

\section{Hands, feet, and lung function}

SH BAIN, P HELMS, JO WARNER Expected values of lung function in children with respiratory disease are usually predicted from regression equations of the index test on stature or sitting height from cross-sectional data in normal children. In children with congenital or acquired scoliosis, arm span or "uncoiled" stature, derived from the observed stature and the degree of spinal angulation, have been used to predict expected values. We have performed measurements of stature, sitting height, and hand and foot length, along with other anthropometric variables and lung volumes, maximal inspiratory and expiratory flow volume loops, and diffusing capacity (TLCO) in $\mathbf{4 5 5}$ normal school children aged 4-18 years. As in previous studies, lung volumes, maximal flow rates, and TLCO were found to be significantly correlated with stature and sitting height, with almost as good correlations with hand and foot length. Mean residual variances for regressions of lung function data on stature, sitting height, and foot and hand length were $26 \%, 26 \%, 36 \%$, and $41 \%$ respectively. Standard deviations around these regressions were $15.2 \%$ for stature and sitting height, increasing to $18.7 \%$ for foot length and $19.2 \%$ for hand length. In children in whom accurate measurements of stature or sitting height cannot be made, hand or fcot length should prove to be useful in predicting expected lung function.

Bronchial reactivity and rate of decline in $\mathrm{FEV}_{1}$ in smokers and ex-smokers

RG TAYLOR, E GROSS, H JOYCE, F HOLLAND, NB PRIDE We examined the relation between bronchial reactivity and annual rate of decline of height-corrected FEV $\left(\triangle F E V_{1} /\right.$ $\mathrm{ht}^{3}$ ) over 7.5 years in 117 smokers, 71 ex-smokers, and 39 non-smokers. Bronchial reactivity was determined as the concentration $\left(\mathrm{PC}_{20}\right)$ of inhaled histamine sufficient to reduce $\mathrm{FEV}_{1}$ by $20 \%$; subjects were divided into reactors $\left(\mathrm{PC}_{20} \leqslant 16 \mathrm{mg} / \mathrm{ml}\right)$ and non-reactors $\left(\mathrm{PC}_{20}>16 \mathrm{mg} / \mathrm{ml}\right)$. Twenty-nine per cent of smokers, $24 \%$ of ex-smokers, and $5 \%$ of non-smokers were reactors. Smokers who reacted had a lower mean baseline $\mathrm{FEV}_{1}$ in 1982 than non-reactors $(84.6 \%($ SEM $2.7 \%) v 108.5 \%(1.4 \%)$ predicted, $\mathrm{p}<$ $0.001)$ and a faster $\Delta \mathrm{FEV}_{\mathrm{t}} \mathrm{ht}^{3}$ (14.1 (SEM 1.4) $v$ 9.2 $\left.(0.7) \mathrm{ml} / \mathrm{y} / \mathrm{m}^{3}, \mathrm{p}<0.01\right)$. Baseline $\mathrm{FEV}$, correlated with $\mathrm{PC}_{20}$ in smokers $\left(\mathrm{r}_{\mathrm{s}}=0.51\right)$ and ex-smokers $\left(\mathrm{r}_{\mathrm{s}}=0.60 ; \mathrm{p}\right.$ $<0.02$ ); all subjects with $\mathrm{FEV}_{1}<80 \%$ predicted were reactors. In ex-smokers $\triangle \mathrm{FEV}, \mathrm{ht}^{3}$ was similar in reactors and non-reactors $\left(9.0(1.5)\right.$ v $\left.7.4(0.8) \mathrm{ml} / \mathrm{y} / \mathrm{m}^{3} ; \mathrm{p}>0.3\right)$ despite differences in baseline $\mathrm{FEV}_{1}$. The prevalence of reactors was slightly increased among smokers with normal baseline $\mathrm{FEV}_{1}$. The results are compatible with the "Dutch hypothesis" that abnormal bronchial reactivity contributes to accelerated decline of $\mathrm{FEV}_{1}$ in smokers, although the association could be a consequence of a lower $F E V_{1}$. In ex-smokers, however, abnormal reactivity persists but decline in $\mathrm{FEV}_{1}$ is not accelerated.

\section{Need the airway be occluded to measure $P_{0-1}$ ?}

KEVIN JONES, DOUG SHAW, ANTONIO FORESI, TIM HIGENBOTTAM Careful analysis of the breathing pattern in critically ill patients with respiratory disease is important for improving understanding and directing appropriate therapy (Milic-Emili. Lung 1981;160:1-17). Present methods involve the measurement of pressure after a brief but total airway occlusion at the onset of inspiration $\left(P_{0.1}\right)$, which precludes simultaneous measurement of the timing of breathing events and breath-by-breath analysis. We have developed an automated (on line to a microcomputer) method for measuring, breath by breath, pressure profile from the onset of inspiration; tidal volume; instantaneous minute volume; and duration of inspiration, expiration, and the apnoeic pause between breaths. The changes in these measurements with rising end-tidal carbon dioxide have been estimated during carbon dioxide rebreathing in nine normal subjects on four separate occasions on four separate days. End-tidal carbon dioxide correlated with instantaneous minute volume $(r=0.91)$, tidal volume $(r=$ 
0.90 ), and inspiratory pressures measured at 0.1 second ( $r$ $=0.76), 0.2$ seconds $(r=0.85)$, and maximum inspiratory pressure $(r=0.85)$. There was no significant difference between these correlation coefficients $(p>0.05)$. This method may have general value as the early inspiratory pressures $\left(P_{0.1}\right.$ and $\left.P_{0.2}\right)$ appear to reflect respiratory drive and occur before significant change in lung volume occurs.

\section{An optical technique of measuring the change in trunk volume with breathing}

AJ PEACOCK, MDL MORGAN, AR GOURLAY, DM DENISON We have developed a particular optical technique of mapping the size, shape, and position of the thoraroabdominal wall with breathing. The subject stands in a reference frame while a pattern of vertical black and white stripes is projected on to the trunk surface, creating contours of its shape. These contours are photographed simultaneously from in front and behind, and encoded digitally to describe the surface in three-dimensional co-ordinates and reconstruct the trunk in order to measure its total volume, partial volumes, surface area, and cross-sectional area at any level. We have used this method to measure the change in volume of the trunk with expiration while simultaneously measuring expired volume at the mouth. In 54 measurements of respired volume in the 13 subjects (one of whom was scoliotic) correlation between optical and spirometric measurements was $r=0.985$, with an absolute error of 0.171 ( \pm SEM 0.024 1). We conclude that this method of measuring respired volume is sufficiently accurate for clinical purposes and has the advantage that it shows the contribution of each region to the breath.

\section{Mechanisms of paradoxical lateral ribcage motion in patients with airflow obstruction}

JJ GILMARTIN, GJ GIBSON Inspiratory paradox of the lateral ribcage margin in chronic airflow obstruction is usually attributed to abnormal traction on the lower ribcage by contraction of the flattened diaphragm. Since direct evidence is lacking, we have investigated the relationships between dimensional changes and pleural (Ppl) and transdiaphragmatic (Pdi) pressures in 10 patients with demonstrable lateral paradox. The lateral diameter of the ribcage was measured at two levels by magnetometry during tidal breathing and voluntary relaxation. Paradox was more evident in the lower ribcage in eight of the 10 patients; it typically begins at the start of inspiration, but in late inspiration the diameter usually increases. Relating the dimensional and pressure changes indicated that the maximum distortion corresponded in most patients to peak values of both Pdi and Ppl but the relation to Pdi was more clearcut, consistent with contraction of the flattened diaphragm as the main mechanism. Paradox of the upper lateral dimension was less clearly attributable to Pdi or Ppl. During diaphragmatic relaxation at full inflation the lateral ribcage diameters increased in all patients, but in some subjects the relaxed dimensions were greater still at volumes below
TLC, suggesting that distortions may also result from the hyperinflation per se, in addition to the effects of active diaphragmatic contraction.

\section{Respiratory movements before and after high thoracic cord compression}

P HELMS, D HEAF, S JOLLY, J WARNER, M GREEN During normal inspiration diaphragmatic contraction increases thoracic volume by displacement of the abdominal contents and elevation of the rib cage. Although the effects of diaphragmatic paralysis on the pattern of thoracoabdominal motion are well known, opportunities to observe the effects of chest wall (intercostal and abdominal muscle) paralysis alone are less common. Video recordings of tidal breathing were made in an otherwise normal 2-month-old male infant recovering from staphylococcal pneumonia, as part of a teaching library of normal and disturbed respiratory patterns. Between the age of 9 months and 1 year this infant developed a dense paraplegia with a sensory level at the second thoracic segment. Radiographs of the spine revealed a subluxation of thoracic vertebra T2 on T3 with severe cord compression at this level. Halopelvic traction was applied and anterior and posterior spinal fusions were performed. We repeated video recordings of his respiratory pattern together with measurements of abdominal and ribcage motion using magnetometers and intrathoracic and abdominal pressures using catheter-mounted balloons. During inspiration the abdomen moved outwards owing to the descent of the diaphragm while the ribcage appeared to be passively driven by the fall in intrathoracic pressure and moved paradoxically inwards. We present video recordings of the respiratory movements in this infant taken before and after cord compression together with the movements of a 9 month-old infant with bilateral diaphragmatic paralysis for comparison.

\section{Is bronchiolectasis reversible after intermittent positive-pressure ventilation with PEEP?}

D LYONS, M NAVARATNARAJAH, JS MILLEDGE, JF NUNN Bronchiolectasis (dilatation of terminal and respiratory bronchioles) has recently been described in a postmortem study of patients who died during or after intermittent positive-pressure ventilation (IPPV) (Slavin et al. $\mathrm{Br}$ Med J $1982 ; 285: 931-4)$. The degree of bronchiolectasis was predictable from the duration and level of positive endexpiratory pressure (PEEP). A very large increase in physiological dead space was inferred from measurements of ventilation and arterial carbon dioxide. We studied five patients who required IPPV and PEEP and were treated on the same intensive therapy unit at the same time as those who died. The mean predicted bronchiolectasis score in the survivors was $2 \cdot 6$ (range $2 \cdot 1-3 \cdot 2$ ) compared with $3 \cdot 2$ (range 0-8) for the group that died. All the patients were healthy adults prior to the development of the condition requiring their admission to the intensive therapy unit. None smoked and all appeared to have made a full recovery when seen 18-120 months after discharge. We carried out spirometric testing and measured arterial gases, lung 
volumes, carbon monoxide transfer, and physiological dead space. Two subjects had spirometric values of $3 \%$ below normal range. Mean dead space was $149 \mathrm{ml}$ (range $104-185 \mathrm{ml}$ ); in no case was it above the normal range. We conclude that these subjects do not have measurable evidence of irreversible bronchiolectasis.

\section{Single-point in vivo calibration improves the accuracy of transcutaneous oxygen tension (tcPo $)_{2}$ ) estimations in adult patients}

BJ GRAY, RW HEATON, AF HENDERSON, DCS HUTCHISON EStimations of arterial oxygen tension $\left(\mathrm{PaO}_{2}\right)$ in adults with transcutaneous electrodes calibrated by in vitro methods lack sufficient accuracy for clinical purposes. We studied 14 patients with indwelling arterial cannulas in whom it was possible to vary the inspired oxygen concentration $\left(\mathrm{F}_{1} \mathrm{O}_{2}\right)$, and thus obtain a range of $\mathrm{PaO}_{2}$ values. An oxygen electrode heated to $45^{\circ} \mathrm{C}$ was calibrated in vitro, applied to the skin, and allowed to reach a stable $\mathrm{tcPO}_{2}$ reading. In vivo calibration was then achieved by adjusting the $\mathrm{tcPO}_{2}$ reading to correspond to the $\mathrm{PaO}_{2}$ of a simultaneous arterial blood sample. $\mathrm{tcPO}_{2}$ and $\mathrm{PaO}_{2}$ were then compared at several points in each patient by altering $\mathrm{F}_{1} \mathrm{O}_{2}$ and allowing $\mathrm{tcPO}_{2}$ to reach a new stable level, when it was compared with the $\mathrm{PaO}_{2}$ of a simultaneous arterial sample. Following in vitro calibration the relationship between $\mathrm{tcPO}_{2}$ and $\mathrm{PaO}_{2}$ in the 14 patients is given by the regression equation (in mm Hg) $\mathrm{tcPo}_{2}=0.58 \mathrm{PaO}_{2}+13.4(\mathrm{r}=0.86: \mathrm{p}<$ 0.001 ). Following in vivo calibration the relationship between $\mathrm{tcPO}_{2}$ and $\mathrm{PaO}_{2}$ over the range of values for $\mathrm{PaO}_{2}$ of $50-294 \mathrm{~mm} \mathrm{Hg}$ (77 data points) was given by the equation $t_{c P O}=0.74 \mathrm{PaO}_{2}+21.8(\mathrm{r}=0.986: \mathrm{p}<0.001)$. If the values of $\mathrm{PaO}_{2}$ in the range of $50-120 \mathrm{~mm} \mathrm{Hg}$ (55 data points) are considered separately, the relationship becomes $\mathrm{tcPO}_{2}=0.98 \mathrm{PaO}_{2}+1.61(\mathrm{r}=0.984: \mathrm{p}<0.001)$. With a single point in vivo calibration values for $\mathrm{tcPO}_{2}$ can for practical purposes be considered identical to $\mathrm{PaO}_{2}$ in the range $50-120 \mathrm{~mm} \mathrm{Hg}$.

\section{Sputum leukotrienes in obstructive airways diseases}

BR O'DRISCOLL, O CROMWELL, AB KAY Sputum samples from patients with bronchial asthma, chronic bronchitis, and cystic fibrosis were examined for the presence of leukotrienes $B_{4}, C_{4}$ and $D_{4}$. After ethanol extraction and purification on Amberlite XAD-8 leukotrienes were identified by high-pressure liquid chromatography (HPLC) using the appropriate markers. Fractions from HPLC were also tested biologically with both the Boyden chemotaxis assay and FPL 55712-inhibitable contraction of the isolated guinea pig ileum. LTB 4 was detected in the sputa from patients with bronchial asthma (7/7), chronic bronchitis (4/4), and cystic fibrosis (4/4). In contrast, LTC 4 and $\mathrm{LTD}_{4}$ were not found in 17 asthmatic sputa, although they were detected in one of four bronchitics and 16 of 25 patients with cystic fibrosis. Sputum from 11/17 asthmatics, 4/25 patients with cystic fibrosis, and $2 / 5$ bronchitics contained an anaphylatoxin-like substance. The majority of sputum samples containing $\mathrm{LTB}_{4}$ also possessed an activity with chemical and biological characteristics of the $5 \mathrm{~S}$, 12S-6, trans-LTB ${ }_{4}$ isomer. These studies indicate that $\overrightarrow{\vec{D}}$ lipoxygenase products of arachidonic acid metabolism are present in the sputum in various forms of obstructive airways disease. The failure to detect the "SRS-A" leukotrienes in sputum in bronchial asthma may be attributable to either losses during extraction, the insensitivity of the assay procedure, or more rapid catabolism of $\mathrm{LTC}_{4}$ and $\mathrm{LTD}_{4}$ by bronchial secretions in bronchial asthma than in cystic fibrosis.

Sputum histamine in acute asthma, chronic bronchitis, and pneumonia measured by five difierent assay techniques

DJR MORGAN, I MOODLEY, RJ DAVIES Mediators derived from mast cells are thought to be important in the pathogenesis of extrinsic asthma. Studies on the measurement of peripheral blood histamine in patients with asthma have shown significantly higher levels at the time of admission to hospital than in other acutely ill patients. However, recent work suggests that the histamine measured in blood may be derived from circulating basophils. For this reason mediators have also been measured in secretions. Previous studies have shown that substantial quantities of histamine can be found in sputum, though there is disagreement as to whether the levels of this mediator are higher in asthmatic patients' sputum than in sputum from patients with bronchitis or pneumonia. We have compared histamine levels in sputum from patients with acute exacerbations of asthma, chronic bronchitis, and pneumonia using a biological assay, a fluorometric assay, two radioenzymatic assays, and a high-pressure liquid chromatography assay. There is marked variation in the amount of histamine found, depending on the technique employed. The highest quantity is found by the fluorometric method, the lowest by the double-isotope radioenzymatic assay (DIREA). Significant inter-assay difference is present in measurements of histamine in biological fluids, despite a close and significant correlation between the assays when histamine is measured in Tyrode's solution $(r=0.9, p<0.05)$. Histamine was measured in the sputum of 10 asthmatic, 10 bronchitic, and 10 pneumonic patients with the DIREA, and was found in all groups $(109.2 \pm 27.8 \mathrm{ng} / \mathrm{g})$ with no significant inter-group difference. Sputum cytology was performed and cell counts correlated with histamine levels.

Assessment of the clinical value of the measurement of serum type III procollagen peptide levels in cryptogenic fibrosing alveolitis.

JME KIRK, GJ LAURENT, ED BATEMAN, PL HASLAM, M TURNER-WARWICK The variability of prognosis and $\underset{<}{ }$ response to treatment in cryptogenic fibrosing alveolitis 0 (CFA) has led to studies suggesting that patients with $\overline{\mathscr{D}}$ "active" CFA have increased type III collagen in the lung (Bateman et al. Thorax 1983;38:93-101), the proportion of which is mirrored by serum levels of its synthetic byproduct type III procollagen peptide (PCP) (Kirk et al. Am Rev Respir Dis in press). To assess the value of PCP levels 
in the management of CFA we measured levels in 60 patients with CFA and 45 controls. In 17 patients, levels were measured prior to commencement of treatment with steroids and/or cyclophosphamide and three to six months thereafter. Physiological measurements were made at six and 12 months. The mean PCP in controls was $8.8 \pm 2.3$ SD and 12.9 \pm 3.5 in the untreated CFA group. Following treatment $14 / 17$ patients showed a decreased $\mathrm{PCP}$, which if more than $25 \%$ was accompanied by a greater than $5 \%$ improvement in the percentage Kco (the corrected transfer factor) ( $p<0.001)$ and forced vital capacity ( $p$ $<0.005$ ). This percentage change in PCP also correlated significantly with the physiological changes found at 12 months $(p<0.01)$. These results suggest that changes in PCP levels follow treatment response, and also imply that interference with type III collagen synthesis is important in the treatment of CFA.

Pulmonary metabolism of immunoreactive prostaglandin $F$ in the healthy and diseased lung and pulmonary circulation

RM JENKINS Much evidence has now accumulated that the lungs and pulmonary circulation of both mammals and man are responsible for the metabolism of a wide range of endogenous circulating substances. Included is the removal of a significant proportion of circulating prostaglandins. There is evidence that these normal metabolic activities are disturbed in pulmonary hypertension and chronic lung disease in man but these previous studies have involved the intravenous administration of bolus pharmacological doses of tritiated prostaglandins. I estimated plasma concentrations of immunoreactive prostaglandin $F$ in pulmonary artery and left ventricular samples, and calculated transpulmonary differences, clearance, and release rates in six patients with primary and secondary pulmonary hypertension, six patients with chronic obstructive lung disease with cor pulmonale, and 15 control subjects. A significant transpulmonary fall was observed in the control group, indicating clearance of prostaglandin $F$ during passage through the pulmonary circulation. In both patient groups, however, the transpulmonary differences were reversed, indicating net release of prostaglandin $F$ by their lungs. These data suggest that diseases involving the pulmonary circulation are associated with a disturbance in the balance between uptake and release of prostaglandins by the pulmonary endothelial cells. This disturbance in normal metabolic activity may aggravate existing pulmonary hypertension and have important systemic effects.

\section{Effect of gas phase of cigarette smoke on lung epithelial permeability}

CDR BORLAND, AT CHAMBERLAIN, TIM HIGENBOTTAM Cigarette smokers have increased lung epithelial permeability, demonstrated by low clearance half-times from lung to blood (T1/2LB) of diethylene triamine penta-acetic acid labelled with technetium-99 m (99mTc-DTPA). On abstention from smoking $T^{1} 1 / 2$ LB rapidly returns towards normal (Minty BD, Jordan C, Jones JG. Rapid improvement in abnormal pulmonary epithelial permeability after stopping cigarettes. Br Med J 1981;282:1183-6). Six normal male cigarette smokers who wished to stop smoking were recruited. They received nicotine chewing gum (Nicorette) throughout the study. Subjects continued to smoke for the first week, all cigarettes being smoked via a Cambridge filter, which effectively excludes particulate matter. During the second week subjects completely abstained from cigarettes. $T^{1} / 2$ LB was measured at recruitment and at the end of weeks 1 and 2 . Abstinence at the end of week 2 was confirmed by measuring expired carbon monoxide. Mean $\mathrm{T}^{1 / 2} \mathrm{LB}$ was 11.8 minutes at recruitment, 10.7 minutes at the end of week 1 (NS), and 19.8 minutes at the end of week $2(p<0.001$ with two-way analysis of variance). Our results suggest that the gas phase of cigarette smoke is responsible for the increased lung epithelial permeability observed in smokers. We do not yet know, however, whether abnormal lung permeability is related to subsequent development of lung disease in cigarette smokers.

\section{Immunofiuorescence studies of parietal pleural capillaries in patients with pleural effusion}

EW BENBOW, BC LEAHY, KJ WOOD, E BENJAMIN, G WILLIAMS, TB STRETTON We have investigated the possibility that. pleural capillary damage by immune complexes may participate in the pathogenesis of exudative pleural effusion of various aetiologies. Pleural biopsy samples were obtained from 26 patients with pleural effusion. These were examined by conventional light microscopy and by immunofluorescence; for the latter method fluoresceintagged antibodies to immunoglobulins IgG, IgA, and IgM and to $\mathrm{Clq}$ and $\mathrm{C} 3$ components of complement were used. Of the 26 biopsy samples examined, 17 were suitable for study as intact pleural capillaries were seen in the tissue sample. Nine samples showed capillary deposits. Of the nine, five showed deposits of $\mathrm{IgM}$; these were all from patients with malignant effusions. The four other positive samples revealed complement only; they were from patients with tuberculosis, pulmonary infarction, and empyema and a patient whose effusion was labelled "idiopathic" after full investigation. Eight biopsy samples did not reveal capillary deposits. Four were from the four patients with transudative effusion, two were from patients with malignant disease, and two from "idiopathic" cases. Thus immune complexes are seen in pleural capillary walls of patients with exudative effusions and may have a role in the pathogenesis of the effusion.

Effects of inhaled histamine, salbutamol, and beclomethasone dipropionate on lung epithelial permeability

PJ REES, D SHELTON, N EISER, TJH CLARK NM MAISEY Lung epithelial permeability has been shown to be increased in cigarette smokers and in asthmatic subjects. We have investigated the effects of inhaled salbutamol, beclomethasone dipropionate (BDP), and histamine on lung 
permeability. Permeability was measured with a scintillation counter over the right upper lobe after inhalation of diethylene triamine penta-acetic acid labelled with technetium- ${ }^{99 \mathrm{~m}}$ Tc-DTPA). An estimate of background tissue activity was obtained by comparing counts from the lung probe and a scintillation counter over the left thigh. Permeability was measured as the half-time clearance of ${ }^{99 m}$ Tc-DTPA from the right upper lobe. The coefficient of variation of the clearance was $14 \%$. In six normal subjects inhalation of $1 \mathrm{mg}$ salbutamol from a metered-dose inhaler 20 minutes before ${ }^{99 m}$ Tc-DTPA had no effect on the clearance, neither did inhalation of salbutamol $200 \mu \mathrm{g}$ four times a day for one week or BDP $100 \mu \mathrm{g}$ four times a day for two weeks. Inhalation of histamine 20-40 minutes after ${ }^{99 \mathrm{~m}}$ Tc-DTPA produced a mean peak flow decrease of $60 \%$, while half-time clearance fell by a mean of $30 \%$. An increased epithelial permeability in asthmatic subjects might allow increased penetration of inhaled antigen or inflammatory mediators. Our results show that a similar increase in permeability occurs on bronchoconstriction with inhaled histamine. Inhaled asthma therapy with salbutamol and BDP has no effect on permeability in normal subjects.

\section{Can the spread of bronchial carcinoma be predicted by a single blood test?}

MARY CARROLL, MARGARET E HODSON, AB KAY A test of leucocyte function (complement receptor enhancement-CRE) was performed on blood monocytes from 38 patients with suspected bronchial carcinoma in whom this diagnosis was subsequently substantiated. In 31 $(81.5 \%)$ the values were below a normal range previously established for monocytes from healthy controls (37) and patients with other non-malignant respiratory diseases (9). By chest radiography and a combination of tomography, liver scan, bone scan, brain scan, computed tomography scan, mediastinoscopy, and operative assessment where appropriate, it was ascertained that all of the 31 patients with reduced CRE had either local or widespread metastasis. In contrast, abnormalities in a single routine haematological or biochemical test in the 38 patients at the time of presentation were as follows: haemoglobin 15 (39\%), ESR $11(29 \%)$, bilirubin $7(18 \%)$, aspartate transaminase $7(18 \%), \gamma$-GGT $12(31.6 \%)$, alkaline phosphatase $11(29 \%)$, and calcium $3(7 \%)$. These results suggest that CRE is a reliable predictor of the extent of this disease since low values were associated with extension within the chest and very low values with widespread metastasis.

\section{Tumour growth and cell loss in human pulmonary neoplasms}

KM KERR, D LAMB Actual volume doubling time (DTact) can be obtained for human pulmonary neoplasms by the technique established by VP Collins et al (Am J Roentgenol 1956;76:988), using measurements taken from lesions on serial chest radiographs. Tumour growth can be investigated at a cellular level after radioactive labelling of
S-phase cells in vitro with tritiated thymidine. The percentage of cells labelled with thymidine, autoradiographically detected on histological sections, is termed the thymidine labelling index (TLI). TLI relates to tumour cell proliferation within a neoplasm and from this a theoretical or potential doubling time (DTpot) may be derived (Steel GG Eur $J$ Cancer 1967;3:381). Differences between DTact and DTpot are attributed to cell loss from the tumour. The cell loss factor, $\phi$, derived by Steel, expressing cell loss as a fraction of cell production, has not previously been estimated for human pulmonary tumours. We have made such estimates for 14 primary and three secondary carcinomas of the lung. All primary bronchogenic carcinomas have $\phi$ values over $70 \%$. Sixty four per cent have values of $90 \%$ or more. A correlation exists between $\phi$ and both degree of tumour differentiation and tumour TLI. Cell loss from the tumour is a major determinant of the actual growth rate of human pulmonary tumours.

\section{Efifect of cysteine derivatives on glycoprotein secretion} into the rat trachea

NC TURNER, C MARRIOTT R Martin et al (Am Rev Respir Dis 1980;121:495) have reported that in vitro $\Phi$ $\mathrm{N}$-acetylcysteine (NAC) decreases the elasticity of mucus,

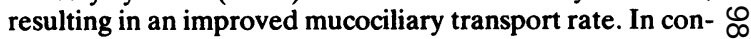
trast, $S$-carboxymethylcysteine (SCMC) has no effect on $\omega$ either mucus properties or mucociliary transport rate and $\square$ its reported effectiveness in vivo must be due to a mechanism unrelated to direct mycolytic activity. In the study described here the effects of systemically administered SCMC and NAC on the basal rate of glycoprotein secretion and on the increase in glycoprotein secretion elicited by intravenous infusion of pilocarpine $\left(4 \times 10^{-6} \mathrm{~mol} / \mathrm{kg} / \overline{\bar{O}}\right.$ min) have been investigated in the rat trachea. A segment of trachea with the collateral arteries and nerves intact was isolated in situ and perfused with physiological saline solution warmed to $37^{\circ} \mathrm{C}$ and pregassed with $95 \% \mathrm{O}_{2}, 5 \%$ $\mathrm{CO}_{2}$. NAC or SCMC was given by continuous intravenous infusion immediately after surgery and pilocarpine infusion was commenced two hours later. The tracheal perfusates were changed every $\mathbf{3 0}$ minutes and assayed for glycoprotein and protein content. The basal rate of glycoprotein secretion into the tracheal segment was $94 \pm 13 \mu \mathrm{g} \delta$ hexose/30 mins, this rate of secretion was reached within the two-hour control period and remained in this range for 0 the remainder of the experiment ( 3 hours). Intravenous infusion of pilocarpine elicited an increase in secretory $\frac{7}{2}$ rate, which reached a peak usually within 90 minutes. The mean maximum increase in secretory rate was $108.25 \pm \mathrm{N}$ $23.4 \mu \mathrm{g}$ hexose/30 min. Neither SCMC (5.5 $\times 10^{-6}, 5.5 \times$

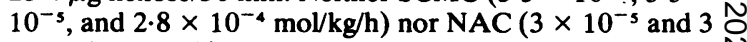
$\times 10^{-4} \mathrm{~mol} / \mathrm{kg} / \mathrm{h}$ ) caused any reduction in the basal rate of $\mathrm{N}$ glycoprotein secretion; however, SCMC $5.5 \times 10^{-5}$ and $\sigma$ $2.8 \times 10^{-4} \mathrm{~mol} / \mathrm{kg} / \mathrm{h}$ and NAC $3 \times 10^{-4} \mathrm{~mol} / \mathrm{kg} / \mathrm{h}$ produced a significant reduction in the secretory response to pilocarpine. Neither drug had any effect on the amount of $\mathbb{D}$ protein in the perfusates. In conclusion, both cysteine derivatives produced a reduction in glycoprotein secretion which is unrelated to their direct effects on mucus. SCMC was approximately 10 times more potent than NAC. 
Histological features of small-cell carcinomas and survival after surgical resection

DJL MALONEY, GN MORRITT, PR WALBAUM, D LAMB Sections from 854 thoracotomies for lung cancer from 1968 to 1972 have been reviewed. One hundred and thirty-five smallcell carcinomas were identified, of which 99 had been resected. The identification of 135 small-cell carcinomas required a change from the histological cell type originally allocated in over $20 \%$ of cases. The small-cell carcinomas were subdivided into the two main subgroups recognised in the 1981 2nd edition of the WHO Classification of Lung Tumours: "oat-cell carcinoma" and "intermediate cell type." Other histological features such as tumour necrosis, presence of DNA cuffing around vessels, and the presence of differentiation as shown by rosette formation were studied and an attempt was made to correlate the histological features with survival after resection. Comparing the 14 survivors with the patients who had resections but did not survive five years showed similar proportions of oatcell and intermediate cell type but the survivors included more who showed necrosis with DNA cuffing, particularly among the oat-cell subgroup. Problems in diagnosing small-cell carcinoma are discussed, particularly the identification of the group of atypical carcinoid tumours which have histological features in common with small-cell carcinoma but a much better prognosis-namely $45 \%$ five-year survival after surgery.

\section{Quality of life after surgical treatment for oesophageal carcinoma}

R COX, CE NEWMAN, HR MATTHEWS Quality of life following surgical treatment has been quantitated prospectively in 100 consecutive new cases of oesophageal carcinoma. Physical activity was graded $0-5$ on a scale of increasing disability, and eating ability similarly. The general sense of wellbeing was graded subjectively and objectively as "good," "fair," or "poor." Parameters were assessed prior to treatment and for a minimum of two years or until death. The principal findings are: (1) Only 19 patients reached a good quality of life following treatment. Seventeen of these were among the 28 patients who were resected, and two were among 18 patients treated initially by dilatation. (2) Only four patients resumed paid employment. All were from the 17 with a good result following resection, of whom 14 were of preretirement age. (3) Recovery time following oesophagectomy for these 17 ranged from six weeks to nine months (mean 3.8 months). (4) Of 29 patients treated by endoscopic intubation, none achieved good parameters and results for quality of life and survival were better in 18 patients treated initially by dilatation alone. This study confirms the generally poor results in this disease except in patients who have complete resection of their tumours, and should provide a baseline for a search for better methods of treatment.
Modified Pearson gastroplasty in the management of the short oesophagus

MK REILLY, HRJ PAYNE, K JEYASINGHAM Surgical treatment of the strictured and shortened oesophagus remains a difficult problem. The desirability of preserving a functional oesophagogastric junction led to development of oesophageal lengthening procedures. Since $1980 \quad 12$ patients with dilatable stricture and shortening of the oesophagus have undergone Collis-Belsey (Pearson) gastroplasty at Frenchay Hospital. A criticism of Pearson's procedure is loss of fundal area coupled with distortion produced by the longitudinal suture line, making an adequate wrap difficult. Modification by transverse closure of the gastric suture line has been developed in order to increase the available surface. Five patients underwent the modified procedure while seven had a standard Pearson gastroplasty. Postoperative evaluation included manometry, barium studies, and oesophagoscopy. Barium studies revealed reduction of the hernia and adequate angulation of the neo-oesophagogastric junction in all but one. Manometry in patients undergoing the modified Pearson gastroplasty identified a lower oesophageal sphincter zone of high pressure with normal relaxation. Acid clearance was normal. Only one patient who had a standard Pearson procedure had a normal sphincter pressure zone with normal relaxation. Acid studies gave normal results in only one. While full evaluation must await long-term results, early indications are that this modification is a useful alternative to the standard Pearson gastroplasty.

\section{Postintubation tracheal injuries}

K MOGHISSI Postintubation tracheal injuries are infrequent considering the frequency with which intubation and tracheostomies are carried out. The number of patients handled by any surgeon is therefore likely to be limited. During a period of 12 years 70 patients with tracheal lesions were treated surgically in our centre; 49 of these had benign and malignant tumours. The remaining 21 patients, who are the subjects of this presentation, had postintubation injuries. There were 14 men and 7 women. Their ages ranged from 20 to 76 years (average $57 \cdot 2$ years). Anatomopathological studies of the lesion placed them in five groups: subglottic stenosis (2 patients), stenotic lesion at the site of the tracheostomy (5), stenotic lesions below the tracheostomy (9), tracheomalacia below the tracheostomy (2) and low tracheal stenosis (3). Three patients had stenotic lesions in two places; the aetiology will be discussed. In all cases circumferential excision and reconstruction were undertaken; only in one patient was cardiopulmonary bypass used. One patient died in hospital six weeks after operation (mortality $4.7 \%$ ); one patient with subglottic stenosis and tracheostomy for 20 years developed restenosis six months after operation and required retracheostomy; one patient died four years after operation from unrelated bronchial carcinoma. All others (18) are alive and symptom free from one year to 10 years after operation. 
Incidence and recurrence of spontaneous pneumothorax in a defined population

HUGH J THOMSON, ANDREW V FOOTE Many oil companies and airlines stipulate a one-year recurrence-free period after a spontaneous pneumothorax before allowing return to work. A comprehensive survey of first spontaneous pneumothoraces occurring in Grampian Region between January 1977 and July 1982 found a total of 227 cases, with an average annual incidence of $87 \cdot 3 /$ million population. Eleven patients had fibrotic or malignant lung disease or acute infections, and the remainder fell into two groups according to age. One hundred and twenty-two patients were under 40 years old: 13 were managed conservatively, and 109 by intercostal drainage; 11 required poudrage or pleurectomy for continuing air leak, and the recurrence rate at five years was $\mathbf{3 0 \%}$. Ninety-four patients were aged 40 years or more; six were managed conservatively and 88 by intercostal drainage; nine died and 14 required poudrage or pleurectomy for persistent leak. A quarter of survivors had a recurrence within five years. Recurrences continued to occur throughout the follow-up period, and it is clear that a one year recurrence-free period in industry is inadequate.

\section{Common childhood respiratory illnesses and subsequent development of lung function}

P HELMS, SH BAIN, JO WARNER There is evidence that respiratory illnesses in early childhood may result in residual disturbances of lung function. We have performed measurements of static and dynamic lung volumes, airway mechanics, gas mixing, and gas exchange in a crosssectional study of apparently fit schoolchildren. To date, 401 children aged 4-18 years have been studied, on whom a detailed questionnaire of birth history, subsequent development, respiratory illnesses, and atopic symptoms had been completed by each child's parents. Of this group, $210(52.3 \%)$ had a history of at least one significant respiratory or atopic illness. The separate categories and their incidence in the whole group were as follows: "croup" $13(3.2 \%)$; "wheezing, asthma, or bronchitis" 28 (7\%); "hay fever and/or eczema" 39 (9.7\%); "pertussis" $30(7.5 \%)$; any combination of the above $93(23.2 \%)$. No significant differences were found between the symptomfree and symptomatic groups for lung volumes, peak inspiratory and expiratory airflow, airflow at $50 \%$ and $25 \%$ of expired vital capacity (VC), accessible lung volume, or carbon monoxide diffusing capacity. However, in 91 children above the age of 9 years a significantly lower airflow at $25 \% \mathrm{VC}$ was observed in the respiratory illness group $(\mathrm{p}<0.02)$. The divergence of the two groups in mid to late childhood suggests a subtle but significant disturbance of lung function, which further cross-sectional and longitudinal studies should clarify.

\section{Does whooping cough damage the lungs?}

IDA JOHNSTON, S PATEL, HR ANDERSON, HP LAMBERT The recent large increase in the incidence of whooping cough has provoked concern about possible long-term effects on the lungs. We have investigated this question by comparing three groups of primary school children with previous 0 whooping cough with controls of the same sex and school $\frac{\tau}{\sigma}$ class by means of a respiratory questionnaire completed by $\overline{\bar{\omega}}$ parents, physical examination, and spirometry (Vitalo- $\overrightarrow{\mathbb{D}}$ graph). The three groups comprised 148 children who had $\varrho$ been hospitalised with whooping cough, 135 who had been notified by their GP, and 77 reported as having had whoop- $\vec{\circ}$ ing cough by their parents in the self-completed question-? naire. Previous chest illnesses other than whooping cough $\overrightarrow{\vec{\omega}}$ and current respiratory symptoms were more frequent $\omega$ among whooping cough children than controls-for exam- $\overrightarrow{\vec{\sim}}$ ple croup $(18 \% \vee 9 \%, \mathrm{p}<0.05)$ and wheeze in the past 12 months $(25 \% v 12 \%, \mathrm{p}<0.001)$. Analysis of the ages at $\infty$ which other chest illnesses occurred relative to the age at 6 which whooping cough occurred suggested that children who have the disease have a pre-existing susceptibility to

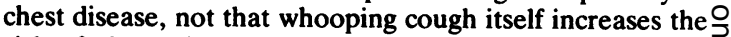
risk of chest disease. When height was controlled for as necessary, analysis of covariance showed no significant dif- $C S$ ferences in $\mathrm{FEV}_{0.75}, \mathrm{FEV}_{1.0}, \mathrm{FVC}, \mathrm{FEV}_{1.0}, \%, \mathrm{FEF}_{25-75 \%}$, or $\frac{\mathbb{D}}{\mathrm{O}}$ mean transit time between cases and controls in any of the $\mathbb{\mathbb { D }}$ three whooping cough groups. We conclude that in the 3 general population whooping cough is unlikely to cause subsequent lung disease.

\section{Prolonged efiects of erythrapheresis in patients with polycythaemia secondary to hypoxic lung disease}

JA WEDZICHA, FE COTTER, RM RUDD, AC NEWLAND, Dw⿳⺈冖𠃌 EMPEY With erythrapheresis, a method of isovolaemic $\varrho$ haemodilution, we can obtain satisfactory reductions of $\overrightarrow{\vec{\sigma}}$ packed cell volume in patients with polycythaemia secon- 3 dary to chronic obstructive bronchitis, with increases in exercise tolerance and mental alertness. To investigate whether these improvements are maintained, we assessed 16 patients (mean $\mathrm{FEV}_{1} 0.841 ; \mathrm{PaO}_{2} 7.0 \mathrm{kPa}$ ) at monthly intervals following erythrapheresis. After treatment the mean microhaematocrit decreased from 0.59 to 0.46 with a $\times$ rise to only 0.51 at the three-month follow-up. The mean blood viscosity at both high and low shear rates was still.

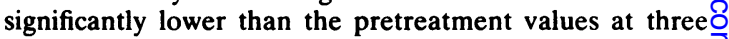
months $(p<0.01)$, with no change in platelet count. There were significant decreases in mean corpuscular volume을 (MCV) (from 93 to $87 \mathrm{fl}$; $<0.001$ ) and mean cell haemoglobin concentration (MCHC) (from 32.1 to 30.50 $\mathrm{g} / 100 \mathrm{ml} ; \mathrm{p}<0.05)$; iron supplements were not administered. Following erythrapheresis the mean six-minute $\stackrel{\sim}{\sim}$ walking distance increased from $351 \mathrm{~m}$ to $429 \mathrm{~m}$ (p r 0.01 ), and at three months it was still significantly greater $(400 \mathrm{~m})$ than the pre-treatment walking distance $(p<\omega$ 0.05). Improvement in scores for three tests of mental alertness was maintained at the three-month follow-upe assessment $(p<0.05)$. By six months after the original $\frac{C}{\mathscr{D}}$ erythrapheresis polycythaemia $(\mathrm{PCV}>0.54)$ had recurred $\stackrel{\Phi}{\rightarrow}$ in eight patients and further treatments were required. Reduction in packed cell volume is, however, maintained for a prolonged period following erythrapheresis with sustained benefit in exercise capacity and mental alertness. 
Almitrine reduces the frequency and severity of recurrent transient nocturmal hypoxaemia in chronic bronchitis and emphysema

JJ CONNAUGHTON, AD MORGAN, NJ DOUGLAS, CM SHAPIRO, N PAULY, DC FLENLEY Almitrine is a triazine derivative which significantly improves arterial gas tensions with minimal change in resting ventilation in hypoxic patients with chronic bronchitis and emphysema. Episodes of recurrent transient hypoxaemia, which may be important in the development of pulmonary hypertension and cor pulmonale, are frequent during nocturnal sleep in such "blue and bloated" patients. In a placebo-controlled doubleblind crossover study we have measured ear oxygen saturation $\left(\mathrm{SaO}_{2}\right)$ and EEG sleep during nocturnal sleep in six patients (3M: 3F; 50-68 years) with chronic bronchitis and emphysema $\mathrm{FEV}_{1} 0.66 \pm 0.221, \mathrm{VC} 2.08 \pm 1.01, \mathrm{PaO}_{2}$ $\left.7.15 \pm 1.02 \mathrm{kPa}, \mathrm{PaCO}_{2} 6.38 \pm 0.35 \mathrm{kPa}\right)$ after two weeks of almitrine (50 mg twice daily). Arterial $\mathrm{PO}_{2}$ when they were awake improved significantly $(p<0.01)$ after almitrine $\left(\mathrm{PaO}_{2} 7.92 \pm 0.94 \mathrm{kPa}\right.$ after almitrine, $\mathrm{PaO}_{2} 7 \cdot 10 \pm$ $1.0 \mathrm{kPa}$ after placebo). Mean $\mathrm{SaO}_{2}$ awake was higher (NS) after almitrine $(89 \% \pm 9.6 \%)$ than after placebo $(84 \% \pm$ $13 \%)$. The mean lowest $\mathrm{SaO}_{2}$ recorded during a night's sleep rose significantly $(p<0.05)$ from $62 \% \pm 22 \%$ after placebo to $76 \% \pm 10 \%$ after almitrine. The mean number of transient hypoxaemic episodes (fall in $\mathrm{SaO}_{2} \geqslant 10 \%$ ) each night was significantly reduced from $2.5 \% \pm 1.6$ after placebo to $0.7 \% \pm 0.5$ after almitrine. The patients slept on average 199 minutes after almitrine and 191 minutes after placebo. Less time on average was spent in wakefulness and drowsiness (Stages 0 and 1) after almitrine (225 minutes) than after placebo (308 minutes). We conclude that oral almitrine may be of value in reducing the number and severity of recurrent transient hypoxaemic episodes during sleep in patients with hypoxic chronic bronchitis and emphysema.

Is mood change linked to improvement of chronic airflow limitation after corticosteroid therapy?

DM MTCHELL, P GILDEH, WAC MCALLISTER, M REHAHN, $K$ DIMOND, P NOBLE, JV COLLINS Corticosteroids may produce mood changes. This might account for improvement in chronic airflow limitation following a trial of steroids as mood elevation could improve performance in objective measurements. This was tested in 21 patients who had detailed psychological assessment during a randomised and controlled double-blind crossover study of the effect of prednisolone $40 \mathrm{mg} /$ day and placebo on chronic airflow limitation. Patients rated themselves on visual-analogue scales for cheerfulness, optimism, speed of thought, activity, sociability, sexual activity, depression, and anxiety before the study and after each phase. Patients also completed a questionnaire designed to detect depression and anxiety. With placebo there was a significant increase on visual-analogue ratings in cheerfulness $(p<0.01)$ and sociability $(\mathrm{p}<0.01)$ and a decrease in depression $(\mathrm{p}<$ 0.01 ). There was also a decrease in depression detected by questionnaire $(p<0.001)$. Following prednisolone the only changes in the group as a whole were decreases in depression ( $p<0.01)$ and anxiety $(p<0.05)$. A small number of patients showed significant $(>20 \%)$ improvements in PEFR, FEV 1 and/or FVC. Nearly all had improvement in one or more of the nine psychological tests following both prednisolone and placebo regardless of physiological response. We conclude that in chronic airflow limitation psychological changes are no more likely with prednisolone than placebo, and that physiological improvement in chronic airflow limitation following prednisolone is not tied to psychological changes.

Controlled study of etoposide and bleomycin combination chemotherapy in squamous-cell carcinoma of the bronchus

PA CORRIS, KW WOODHOUSE, MD RAWLINS, S NARIMAN, GJ GIBSON Non-surgical treatment of squamous-cell carcinoma of the bronchus has had little effect on long-term survival and is usually reserved for symptomatic use. Few controlled studies of chemotherapy have been reported and we have therefore carried out such a study using the theoretically synergistic combination of etoposide and bleomycin. All 43 patients entered were unfit for surgery but on clinical and biochemical criteria disease was localised to the thorax and supraclavicular glands. The patients were randomly allocated to either continued observation or treatment with intravenous etoposide $100 \mathrm{mg} / \mathrm{m}^{2}$ followed six hours later by intravenous bleomycin $10 \mathrm{mg}$ on three successive days; the pulses were given monthly to a total of five. If after randomisation any patients developed a clear indication for radiotherapy this was given to the appropriate site. Of 22 patients in the treatment group, the radiological response was assessable in 17 . Complete radiological remission was achieved in three patients and partial remission in four, while in the control group there was no evidence of tumour regression in any case. Performance status during and after the study was better in the treatment group and the drugs were well tolerated. Median survival was greater than 12 months in the treatment group compared with six months in the control group.

\section{Are transbronchial biopsies clinically valuable?}

PETER BOFFA, RICHARD DENT, TIM HIGENBOTTAM, CHRIS FLOWER, JOHN STARK, JOHN SHNEERSON, PETER STOVIN While it is our practice to use percutaneous needle biopsy aspiration for the diagnosis of discrete peripheral lung lesions, we have performed 204 transbronchial biopsies via the fibreoptic bronchoscope for bilateral diffuse lung disease $(n=114)$ and ill-defined lobar opacities $(n=90)$. In the past two years a follow-up of from 4 to 24 months has enabled us to calculate sensitivity (true positive/true positive + false negative) and predictive value of negative results (true negative/true negative + false negative). All patients were analysed, including the $28 \%$ from whom material for histological examination was inadequate. There was one death from pulmonary haemorrhage (hairy-cell leukaemia) and two pneumothoraces. In diffuse disease sensitivity was $84 \%$ for sarcoid $(n=31), 75 \%$ for 
malignancy $(n=16)$, and $84 \%$ for infection (mainly in the immunosuppressed) $(n=15)$, but it was $34 \%(n=22)$ for fibrosing alveolitis and only $10 \%$ for vasculitic and granulomatous disease $(n=10)$. Sensitivity in lobar disease was $52 \%$ for malignancy $(n=42), 55 \%$ for infections $(n=9)$, and zero for vasculitic lesions $(n=2)$. Transbronchial biopsy is valuable in diagnosing sarcoidosis, malignancy, or infections producing diffuse lung shadowing. The predictive value of negative results in cases of diffuse shadowing was poor $(=0.38)$, but with lobar opacities negative results had more predictive value $(=0.58)$ though the method was not particularly sensitive in diagnosis.

\section{Open lung biopsy in patients with diffuse intrapulmonary shadowing}

GRAHAM E VENN, PHILIP H KAY, CAROLINE J MIDWOOD, PETER GOLDSTRAW The radiological appearances of diffuse pulmonary shadowing are not specific and usually histological examination is necessary to provide diagnosis and to demonstrate the activity of the disease process. From July 1980 to May 1983 we performed open lung biopsy in 101 patients. Biopsy was performed through a limited (3$10 \mathrm{~cm}$ ) submammary incision. Twenty-seven patients had undergone prior invasive investigations (transbronchial or drill biopsy). Twenty-seven patients were taking steroids at the time of biopsy $(10-60 \mathrm{mg}$ prednisolone/day). In 92 patients the histological appearances of the biopsy were sufficiently specific to permit diagnosis. Chest infections occurred in six patients, and in eight there was some superficial infection of the wound. These complications were more frequent in those patients taking corticosteroids. The chest drain was removed usually on the first postoperative day. In three patients who were extremely ill with advanced lung disease air leak recurred. There were four deaths in the series, all in patients with severe preexisting lung disease. Death in all cases was related to progression of the underlying pulmonary disease. Open lung biopsy can be performed with minimal morbidity and high diagnostic yield. The approach we have used provides a safe and reliable operation with good cosmetic results.

\section{Open lung biopsy: 158 cases surveyed}

DE STABLEFORTH, KM CITRON, M TURNER-WARWICK One hundred and fifty eight open lung biopsies were carried out on patients ranging in age from 11 months to 74 years (mean 45 years) over a five-year period at the Brompton Hospital. The procedures were performed to make a diagnosis or for staging, sometimes when less invasive methods had failed, principally in patients found to have fibrosing alveolitis $(26 \%)$, malignancy $(36 \%)$, and tuberculosis or sarcoidosis $(11 \%)$. Overall $31(20 \%)$ biopsies were complicated (surgical $11 \%$, anaesthetic $2 \%$, and medical or incidental $8 \%$ ) and three $(1.9 \%)$ patients died within 30 days. Significant wound infection $(5 \%)$, prolonged pneumothorax $(5 \%)$, chest infection, extensive lung collapse, and respiratory failure (5\%) and contralateral tension pneumothorax $(1 \%)$ during anaesthesia were the main events. Seventeen patients were taking corticosteroid drugs at the time of surgery; of these, four $(24 \%)$ developed a pneumothorax requiring prolonged tube drainage and four $(24 \%)$ had "medical" complications, including chest infection. None developed wound infections in this group. The remaining 141 patients received no corticosteroids; of these, only six (4\%) acquired a prolonged pneumothorax, eight $(6 \%)$ had significant wound infection, and $10(7 \%)$ "medical" complications ( $<<$ $0 \cdot 01$ ). Patients in whom surgical staples were used for lung closure (29) fared no differently from those not so treated (129), $6 \%$ of them having prolonged pneumothorax. Likewise the overall complication rate occurring in patients having biopsy through full-sized and limited incisions was not significantly different. Open lung biopsy must clearly be considered in the light of possible benefit, clinical urgency, alternatives if any, and local surgical expertise and then embarked on with the knowledge that there is a significant rate of complications.

\section{Percutaneous Trucut lung biopsy in the diagnosis of localised pulmonary lesions}

BDW HARRISON, RS THORPE, PG KITCHENER, BG MCCANN, JR PILLING Seventy-seven patients with localised lesions on chest radiographs have had percutaneous Trucut biopsies under local anaesthetic and with $x$-ray screening. Tissue was obtained from 74 patients and was diagnostic in 70 (95\%) (57 malignant and 13 non-malignant). Objective histological or cytological confirmation of the diagnosis was obtained for $32 \%$ of the malignant and $38 \%$ of the non-malignant problems. Corroborative clinical evidence was obtained in the remainder. Complications included pneumothorax in 21 patients $(27 \%)$, requiring a tube in four patients; haemorrhage, usually trivial, in 19 , requiring transfusion in one patient; and two needle-track secondaries. The sizes of the masses ranged from 1.5 to $>10 \mathrm{~cm}$ most being $5 \mathrm{~cm}$ in diameter or less; and all but three were 3-10 cm from the skin surface. This is the largest series of cutting needle biopsies performed for diagnosis of localised lesions since 1960 . Recent reviews have emphasised the dangers of this technique on the basis of fatalities, which almost all occurred in patients with diffuse lung disease. Advantages of biopsy over aspiration cytology include cell typing of tumours, accurate diagnosis of benign lesions, and the fact that an expert cytopathologist is not needed. These and important technical details, including indications and contraindications, will be discussed.

\section{Transbronchial biopsies for diffuse lung disease: is $\mathbf{x}$-ray screening necessary?}

D MITCHELL, JE SELF, JG HAY Transbronchial lung biopsy via the fibreoptic bronchoscope is used in some centres to obtain tissue for diagnosis of diffuse lung disease. 
Radiological screening has been recommended to allow accurate forceps placement and to minimise the risk of complications. While screening is clearly necessary for the biopsy of local disease, its role in the diagnosis of diffuse disease has not been established. We have analysed the results of transbronchial lung biopsy without screening in 70 patients at the London Chest Hospital by review of case notes, and assessed the incidence of complications in a further 65 patients at other centres by questionnaire. Blood loss was recorded at the time of the bronchoscopy and a chest radiograph was taken one to four hours after the biopsy in every case. Histological diagnosis was obtained in 42 out of 70 patients $(60 \%)$ overall. The diag- nosis was sarcoidosis in 20 cases, fibrosis in $\mathbf{1 0}$, malignancy in eight, and other conditions in four; the procedure was non-diagnostic in 28 cases. A definite diagnosis was made less frequently-in six out of 14 cases $(43 \%)$ - when the radiographic shadowing was limited to the upper zones. Only three patients had significant complications-namely pneumothorax, pneumonia, bleeding greater than $50 \mathrm{ml}$ respectively. Review of a further 65 transbronchial lung biopsies performed at two other centres without screening revealed no significant complications. This retrospective survey suggests that transbronchial lung biopsy without screening is a reasonably safe procedure with an acceptable diagnostic yield. 